\title{
Analogs of Cinnamic Acid Benzyl Amide As Nonclassical Inhibitors of Activated JAK2 Kinase
}

\author{
Marcin Mielecki ${ }^{1,2}$, Małgorzata Milner-Krawczyk ${ }^{1}$, Krystyna Grzelak $^{1}$, Damian Mielecki ${ }^{3}$, \\ Krystiana A. Krzyśkoo ${ }^{2,4}$, Bogdan Lesyng ${ }^{2,4}$ and Waldemar Priebe ${ }^{5, *}$
}

\author{
${ }^{I}$ Polish Academy of Sciences, Institute of Biochemistry and Biophysics, Protein Biosynthesis \\ Department, Warsaw, Poland; \\ ${ }^{2}$ Polish Academy of Sciences, Medical Research Center, Bioinformatics Laboratory, Warsaw, Poland; \\ ${ }^{3}$ Polish Academy of Sciences, Institute of Biochemistry and Biophysics, Molecular Biology Department, \\ Warsaw, Poland; \\ ${ }^{4}$ University of Warsaw, Faculty of Physics, Department of Biophysics, Warsaw, Poland; \\ ${ }^{5}$ Department of Experimental Therapeutics, The University of Texas MD Anderson Cancer Center, \\ Houston, Texas, USA
}

*Address correspondence to this author at the Department of Experimental Therapeutics, Unit 1950, The University of Texas MD Anderson Cancer Center, 1515 Holcombe Blvd., Houston, TX 77030, USA; Tel: +1 713792 3777; E-mail: wpriebe@mdanderson.org

\begin{abstract}
Scaffold-based analogs of cinnamic acid benzyl amide (CABA) exhibit pleiotropic effects in cancer cells, and their exact molecular mechanism of action is under investigation. The present study is part of our systemic analysis of interactions of CABA analogs with their molecular targets. These compounds were shown to inhibit Janus kinase 2 (JAK2)/signal transducer and activator of transcription 3 (STAT3) and JAK2/signal transducer and activator of transcription 5 (STAT5) signaling and thus are attractive scaffolds for anticancer drug design. To identify the potential mechanisms of action of this class of compounds, direct interactions of the selected CABA analogs with JAK2 kinase were examined. Inhibition of JAK2 enzymatic activity was assessed, and molecular modeling studies of selected compounds-(E)-2-cyano- $\mathrm{N}-[(\mathrm{S})-1$-phenylethyl]-3(pyridin-2-yl)acrylamide (WP1065), (E)-2-cyano-N-[(S)-1-phenylbutyl]-3-(3-bromopyridin-2-yl)acrylamide (WP1130), and (E)-2-cyano-N-[(S)-1,4-diphenylbutyl]-3-(3-bromopyridin-2-yl)acrylamide (WP1702)-in the JAK2 kinase domain were used to support interpretation of the experimental data. Our results indicated that the tested CABA analogs are nonclassical inhibitors of activated (phosphorylated) JAK2, although markedly weaker than clinically tested ATP-competitive JAK2 inhibitors. Relatively small structural changes in the studied compounds affected interactions with JAK2, and their mode of action ranged from allostericnoncompetitive to bisubstrate competitive. These results demonstrated that direct inhibition of JAK2 enzymatic activity by the WP1065 (half-maximal inhibitory concentration $\left.\left[\mathrm{IC}_{50}\right]=14.8 \mu \mathrm{M}\right)$, WP1130 $\left(\mathrm{IC}_{50}\right.$ $=3.8 \mu \mathrm{M})$, and $\mathrm{WP} 1702\left(\mathrm{IC}_{50}=2.9 \mu \mathrm{M}\right)$ potentially contributes, albeit minimally, to suppression of the JAK2/STAT signaling pathways in cancer cells and that additional specific structural modifications may amplify JAK2-inhibitory effects.
\end{abstract}

Keywords: bisubstrate-competitive, CABA, cinnamic acid, inhibitor, JAK2, molecular modeling, noncompetitive, STAT3, STAT5, WP1065, WP1130, WP1702. 


\section{INTRODUCTION}

Janus kinases (JAKs) are important regulators of the cytokine- and growth factor-induced JAK/signal transducer and activator of transcription (STAT) signaling pathways. Ligand binding to transmembrane receptors stimulates autophosphorylation of JAKs, which then phosphorylate STATs. Activated STATs dimerize, translocate to the nucleus, and turn on expression of genes responsible for cell proliferation, survival, differentiation, and apoptosis inhibition [1]. JAK2 has appeared to be an attractive target for downregulation of signaling by the JAK2/STAT pathways, and several therapeutically promising novel JAK2 inhibitors are under clinical investigation [2].

Priebe and co-workers designed and synthesized a novel class of inhibitors of the JAK2/STAT signaling pathways [3-5] using a scaffold of natural compounds structurally related to cinnamic acid benzyl amide (CABA) (Fig. 1). Derivatives of cinnamic acid are important constituents of natural products (e.g., propolis, fruits, vegetables, herbs) and exert many biological activities (thoroughly reviewed in [6]). Their chemopreventive, antiproliferative, antineoplastic, and antimetastatic properties are among the most studied of these activities. These newly designed CABA inhibitors displayed markedly increased anticancer activity in a wide range of in vitro and in vivo tumor models [7-21]. In view of their well-recognized biological activity, systematic assessment of all potential mechanisms of action was important. CABA analogs' ability to block the JAK2/STAT3 and JAK2/STAT5 pathways is clearly a result of multifactorial effects rather than exclusively direct inhibition of JAK2, STAT3, or STAT5 [22-26]. In addition, certain CABA derivatives may interact with targets outside the JAK/STAT pathways as exemplified by the CABA derivative WP1609, which inhibits the activity of the atypical protein kinase Rio1 [27].

To determine the possible contribution of direct JAK2 inhibition to the observed suppression of the JAK2/STAT signaling pathways by CABA analogs, we assessed direct effects of these compounds (Fig. 1) on JAK2's enzymatic activity. We performed studies of in vitro inhibition of the recombinant JAK2 kinase domain by CABA analogs, which demonstrated that six CABA derivatives-WP1065, WP1174, WP1130, WP1682, WP1702, and WP1703-inhibited JAK2-catalyzed phosphorylation of the STAT5 peptide substrate at low micromolar levels (half-maximal inhibitory concentration $\left[\mathrm{IC}_{50}\right]$ range, 2.9-22.1 $\mu \mathrm{M}$ ). This indicated that these compounds are relatively weak JAK2 inhibitors. Furthermore, results of molecular modeling of interactions of selected CABA analogs with the JAK2 kinase domain pointed to ligand-specific mechanisms of binding. Direct but weak inhibition of JAK2 phosphorylation activity may contribute, albeit minimally, to the overall effects of CABA derivatives on the JAK2/STAT3 and JAK2/STAT5 signaling pathways.

\section{MATERIALS AND METHODS}

\section{Expression of the JAK2 Kinase Domain in a Baculoviral System}

A cDNA encoding JAK2 (clone number 6838318; Mammalian Gene Collection EMM10027498663) was purchased from Open Biosystems (Huntsville, Alabama, USA). A kinase domain-coding sequence (nucleotides 2410-3399, amino acids 804-1132) was amplified via polymerase chain reaction using the primers 5'-GATCTTAACAGCCTGTTTACTCCAG-3' and TCACGCAGCTATACTGTCCCGGATTTG-3'. A 1-kb fragment of the JAK2 coding sequence was subcloned into the transfer plasmid pIEx-2 (Novagen, Darmstadt, Germany) in a frame with glutathione $S$ transferase-, S-, and hexahistidine-tag sequences. Subsequently, the whole cassette was subcloned into a pFastBac HT plasmid to introduce it into bacmid DNA via site-specific transposition in the Escherichia coli DH10Bac strain (Invitrogen, Carlsbad, California, USA). Sf21 insect cells were used for transfection and generation of a recombinant baculovirus and for baculovirus amplification and titration. Infection of HF 
insect cells was the final step in the production of a recombinant JAK2 protein. All of these procedures were carried out according to the manufacturer's instructions (Invitrogen).

\section{Protein Purification}

HF cells were lysed via freeze-thaw cycles in a lysis buffer $(50 \mathrm{mM}$ Tris- $\mathrm{HCl}, \mathrm{pH} 8.0,0.05 \mathrm{M} \mathrm{NaCl}$, $1 \%$ isooctylphenoxypolyethoxyethanol [Triton X-100], 1 mM dithiothreitol [DTT], 10\% glycerol) containing a protease inhibitor cocktail (Roche, Indianapolis, Indiana, USA). To reduce the viscosity, the lysate was incubated with Benzonase nuclease $\left(2.5 \mathrm{U} \cdot \mu^{-1}\right.$; Novagen $)$ for 30 minutes on ice. After adding $\mathrm{NaCl}$ to the $0.5-\mathrm{M}$ final concentration, the lysate was clarified $\left(50000 \cdot \mathrm{g}, 60\right.$ minutes, $\left.4^{\circ} \mathrm{C}\right)$, and the supernatant was adsorbed onto glutathione-agarose beads (Sigma-Aldrich, St. Louis, Missouri, USA) for 2 hours at $4^{\circ} \mathrm{C}$. The resin was washed with another buffer $(50 \mathrm{mM}$ Tris- $\mathrm{HCl}, \mathrm{pH} 8.0,0.2 \mathrm{M} \mathrm{NaCl}, 0.1 \%$ Triton X-100, $1 \mathrm{mM}$ DTT, $10 \%$ glycerol). The JAK2 protein was eluted with the wash buffer containing $10 \mathrm{mM}$ reduced glutathione (Sigma-Aldrich). Collected fractions were concentrated and dialyzed on Microcon filters (MWCO, $50 \mathrm{kDa}$; EMD Millipore, Billerica, Massachusetts, USA) against $25 \mathrm{mM}$ Tris-Cl, pH 8.0, $0.2 \mathrm{M}$ $\mathrm{NaCl}, 0.05 \%$ Triton X-100, 1 mM DTT, and 10\% glycerol.

To obtain preautophosphorylated JAK2, an additional step was introduced into the protein purification procedure. Specifically, the lysate was incubated at $4^{\circ} \mathrm{C}$ with $10 \mathrm{mM}$ ATP (Fermentas, Vilnius, Lithuania), $10 \mathrm{mM} \mathrm{MgCl}, 1 \mathrm{mM} \mathrm{Na}_{3} \mathrm{VO}_{4}$, and $5 \mathrm{mM} \mathrm{NaF}$. The magnesium ions and protein phosphatase inhibitors were then maintained in the purification buffers.

The influence of various types of detergents on the stability of the JAK2 kinase domain was analyzed. Recombinant JAK2 bound to glutathione-agarose beads was cleaved with $2.5 \mathrm{U}$ thrombin protease (Sigma-Aldrich) for several hours at $4^{\circ} \mathrm{C}$. The resulting preparations were clarified via microcentrifugation, and the supernatants were analyzed using polyacrylamide gel electrophoresis. The detergents used were Triton X-100 (BDH Chemicals, Radnor, Pennsylvania, USA), 3-(3-cholamidopropyl) dimethylammonio-1propanesulfonate (CHAPS; BioShop, Burlington, Ontario, Canada), polyethylene glycol 400 dodecyl ether (Thesit; Fluka, St. Louis, Missouri, USA), polyoxyethylene (20) sorbitan monolaurate (Tween-20; BioShop), n-dodecyl $\beta$-D-maltoside (DDM; Sigma-Aldrich), and polyoxyethylene lauryl ether (Brij 35; BDH Chemicals).

Protein preparations were analyzed using $12 \%$ sodium dodecyl sulfate (SDS)-polyacrylamide gel electrophoresis (PAGE), and the protein concentration was determined using a protein assay kit (Bio-Rad, Hercules, California, USA) with bovine serum albumin as a standard. Western blot analysis was carried out according to standard procedures with an alkaline phosphatase-conjugated mouse monoclonal anti-6X His tag antibody (HIS-1; Abcam, Cambridge, UK).

\section{Autophosphorylation Activity Assay}

To assess the autophosphorylation activity of JAK2, the 0.4- $\mu \mathrm{M}$ JAK2 recombinant enzyme was incubated in the presence of $\left[\gamma^{32} \mathrm{P}\right] \mathrm{ATP}$ at room temperature with a reaction buffer $(25 \mathrm{mM}$ Tris- $\mathrm{HCl}, \mathrm{pH} 8.0$, $0.15 \mathrm{M} \mathrm{NaCl}, 10 \mathrm{mM} \mathrm{MgCl}_{2}, 0.5 \mathrm{mM} \mathrm{NaF}, 0.1 \mathrm{mM} \mathrm{Na}_{3} \mathrm{VO}_{4}, 5 \%$ dimethyl sulfoxide, $0.05 \mu \mathrm{M}\left[\gamma^{32} \mathrm{P}\right] \mathrm{ATP}$ $\left[0.25 \mu \mathrm{Ci} \cdot \mu \mathrm{l}^{-1}\right.$ in the reaction]). The reaction was stopped with the addition of protein loading dye $(50 \mathrm{mM}$ Tris-HCl, pH 6.8, 2\% SDS, $10 \%$ glycerol, $0.1 \mathrm{M}$ DTT, 0.01\% bromophenol blue). The reaction products were separated via SDS-PAGE. Polyacrylamide gels were stained with Coomassie Brilliant Blue and used to expose a phosphor screen for 30 minutes. Subsequently, the phosphor screen was visualized using an FLA7000IR scanner (FujiFilm, Tokyo, Japan) and analyzed using the MultiGauge software program (FujiFilm). Radiolabeled protein bands of autophosphorylated JAK2 were excised from the gel and dissolved in a mixture of hydrogen peroxide and perchloric acid $(2: 1 \mathrm{v} / \mathrm{v})$. Čerenkov radiation in the bands was measured using a liquid scintillation analyzer (Tri-Carb 2910TR; PerkinElmer, Waltham, Massachusetts, USA), and 
counts per minute were calculated for each reaction variant using the QuantaSmart (version 3.00) and TriCarb LSC software programs (PerkinElmer).

\section{Peptide Tyrosine Phosphorylation Assay}

The catalytic activity of recombinant JAK2 was measured via phosphorylation of the STAT5 peptide (TPVLAKAVDGYVKPQIKQVV; synthesized in the Peptide Synthesis Laboratory of the Institute of Biochemistry and Biophysics, Polish Academy of Sciences) using a kinase reaction buffer (50 $\mathrm{mM}$ Tris-Cl, pH 8.0, $0.15 \mathrm{M} \mathrm{NaCl}, 10 \mathrm{mM} \mathrm{MgCl} 2,0.5 \mathrm{mM} \mathrm{NaF}, 0.1 \mathrm{mM} \mathrm{Na} \mathrm{VO}_{4}, 5 \%$ dimethyl sulfoxide, ATP [Promega, Madison, Wisconsin, USA], STAT5 peptide and $50 \mathrm{nM}$ JAK2 recombinant kinase [preautophosphorylated form]). The concentrations of the substrates (ATP and peptide) varied. The kinase activity was measured using an EnzyChrom kinase assay kit (BioAssay Systems, Hayward, California, USA). The level of ADP was measured using a coupled reaction of pyruvate kinase converting ADP to ATP and pyruvate. The concentration of pyruvate was counted fluorometrically with the excitation and emission wavelengths set at $528 \mathrm{~nm}$ and $590 \mathrm{~nm}$, respectively. This procedure was carried out according to the manufacturer's instructions (BioAssay Systems). The fluorescent intensity of the reaction mixtures was measured in 384-well plates (Greiner Bio-One GmbH, Frickenhausen, Germany) using a Synergy HT-I plate reader (BioTek, Winooski, Vermont, USA) with standard reading parameters.

\section{Statistical Analysis}

Averaged relative fluorescence units corresponding to the JAK2 catalytic activity were plotted against a logarithm of the concentration of the CABA derivatives. The data were fit to a dose-response curve function according to the equation $\mathrm{y}=\mathrm{A} 1+\left([\mathrm{A} 2-\mathrm{A} 1] /\left[1+10^{\wedge}\left(\log _{0}-\mathrm{x}\right) \cdot \mathrm{p}\right]\right)$, in which $\mathrm{A} 1$ is the bottom asymptote, $\mathrm{A} 2$ is the top asymptote, $\log \mathrm{x}_{0}$ is the center, and $\mathrm{p}$ is the Hill slope. The weighting method for the fitting was set to instrumental. The $20 \%$ inhibitory concentration, $\mathrm{IC}_{50}$, and $80 \%$ inhibitory concentration as well as the Hill coefficient, a measure of cooperative binding of ligands, were calculated. Statistical significance was expressed as the $95 \%$ confidence interval (CI) of the fit parameters.

\section{Molecular Docking}

Docking was carried out using the AutoDock software program (version 4.2) [28, 29]. The target protein was the crystallographic structure of JAK2 with the Protein Data Bank database code 2B7A [30]. The target protein was rigid, and the ligands had conformational flexibility. Atomic partial charges were computed using the Gasteiger method. Electrostatic, desolvation, and atomic affinity grid maps for each atom type were constructed. The cubic grid maps were centered on the JAK2 kinase domain cavity and had dimensions of $47 \times 47 \times 47 \AA$ with 0.375 - $\AA$ spacing between the grid points. The Lamarckian hybrid genetic algorithm was used as the search method for low-energy binding conformations with a modified set of parameters. Local search was carried out with standard parameters. A semiempirical free energy force field was used to evaluate conformational energies of the ligands in JAK2 [31, 32]. Clustering analysis of 100 docked conformations was carried out for each ligand.

\section{Geometry Optimization}

Complexes of the JAK2 kinase domain with selected pairs of WP1130 generated in the molecular docking experiments were optimized via energy minimization and simulated annealing simulations performed using Yet Another Scientific Artificial Reality Application. An Amber03 force field was applied $[33,34]$ using the Particle Mesh Ewald algorithm [35] to treat long-range electrostatic interactions with a 7.86- $\AA$ cutoff value. Prior to optimization, virtual titration was performed to set up optimal microscopic 
protonation states. Structures were solvated with a $0.9 \% \mathrm{NaCl}$ aqueous solution ( $\mathrm{pH}$ 8.0) with cell neutralization [36]. Solvated structures were subjected to energy minimization using the steepest descent method followed by a simulated annealing procedure (time step $2 \mathrm{fs}$, atom velocities scaled down by 0.9 every 10th step).

\section{Molecular Dynamics Simulation}

The stability of the complexes of the principal conformation clusters of the selected ligands WP1065, WP1130, and WP1702 with the JAK2 kinase domain (AutoDock initial states) was tested using molecular dynamics (MD) simulations. The same testing was used for complexes of JAK2 and selected pairs of WP1130 after careful geometry optimization using Yet Another Scientific Artificial Reality Application. MD simulations were performed with a water solution for $5 \mathrm{~ns}$ after thermalization and equilibration of the system at $\mathrm{T}=310 \mathrm{~K}$, atmospheric pressure, and salt concentration of 0.05 in a rectangular cuboid. The NAMD library [37], which is capable of carrying out simulations for large molecular systems with scalable parallel MD algorithms, was used. This library was developed by the Theoretical and Computational Biophysics Group at the Beckman Institute for Advanced Science and Technology at the University of Illinois at UrbanaChampaign (http://www.ks.uiuc.edu/Research/namd). The CHARMM27 force field [38] and a TIP3P water model [39] were applied. Parametrization of the ligands was carried out using the ParamChem interface (https://www.paramchem.org) for the CGenFF software program (version 0.9.6) in the CHARMM General Force Field (2b7) [40-42]. Energy analysis was performed for stable complexes in MD simulations. The interaction energy of the ligand-protein and ligand-ligand pairs was averaged over the MD trajectories.

\section{Multiple Sequence Alignment}

Multiple sequence alignment of four human JAK protein sequences-JAK1 (GI: 215274013, P23458.2), JAK2 (GI: 12643404, O60674.2), JAK3 (GI: 50403745, P52333.2), and TYK2 (GI: 56405328, P29597.3) — was performed using the ClustalX2 software program [43] with a gap opening penalty of 10 , gap extension penalty of 0.2 , and identity matrix. The multiple sequence alignment was then processed and visualized using the Geneious 6 software program (Biomatters, San Francisco, California, USA). For improved clarity of the alignment, only C-terminal parts of proteins are shown in Fig. (2A). The residues were colored according to position conservation: $100 \%$, green; $80-100 \%$, dark yellow; $60-80 \%$, yellow; and less than $60 \%$, no color (BLOSUM62 score matrix, threshold set to 4).

\section{CABA Derivatives}

Compounds used in this study were synthesized at the laboratories of Waldemar Priebe and Wiesław Szeja. Chemical structures of the representative compounds listed below are presented in Fig. (1).

WP1055: (E)-2-cyano-N-benzyl-3-(pyridin-2-yl)acrylamide

WP1065: (E)-2-cyano-N-[(S)-1-phenylethyl]-3-(pyridin-2-yl)acrylamide

WP1174: (E)-2-cyano-N-[(R)-1-phenylethyl]-3-(pyridin-2-yl)acrylamide

WP1130: (E)-2-cyano-N-[(S)-1-phenylbutyl]-3-(3-bromopyridin-2-yl)acrylamide

WP1682: (E)-2-cyano-N-[(S)-1-phenylbutyl]-3-(4-bromopyridin-2-yl)acrylamide

WP1702: (E)-2-cyano-N-[(S)-1,4-diphenylbutyl]-3-(3-bromopyridin-2-yl)acrylamide

WP1703: (E)-2-cyano-N-[(S)-1,4-diphenylbutyl]-3-(4-bromopyridin-2-yl)acrylamide

Certain commercially available inhibitors of the JAK2 kinase were included in the study as reference compounds: AG490, (E)-2-cyano-N-benzyl-3-(3,4-dihydroxyphenyl) acrylamide (Sigma-Aldrich), lestaurtinib (CEP701), and tofacitinib (tasocitinib, CP690550) (LC Laboratories, Woburn, Massachusetts, USA). 


\section{RESULTS}

\section{JAK2 Expression and Purification}

To optimize the expression of the JAK2 sequence in insect cells, we determined the kinetics using Western blot analysis with an anti-histidine antibody. The highest concentration of JAK2 in the lysate supernatant was recorded at 24 hours after infection in HF insect cells (Supplementary Fig. 1). Proteolytic degradation 48 hours after infection and accumulation of the JAK2 protein in a lysate pellet, which contributed to reduced levels of the solubilized form of the recombinant kinase, were the consequences of a high instability index for the JAK2 kinase domain (47.84), aliphatic index (83.50), and grand average of hydropathicity (-0.553) [44]. Owing to the high instability and relatively high hydrophobicity of the JAK2 kinase domain, we investigated the influence of several different detergents on the stabilization of recombinant JAK2 in an aqueous solution. To rule out influence of the solubilizing properties of the glutathione $S$-transferase protein, we cleaved the JAK2 kinase domain on glutathione-agarose beads via thrombin-directed proteolysis. Four detergents-Triton X-100, Thesit, DDM, and Brij 35-clearly stabilized the JAK2 kinase domain (Supplementary Fig. 2). Consequently, we used Triton X-100 in all of the purification buffers.

\section{Inhibition of JAK2 Autophosphorylation by CABA Analogs}

We analyzed the autophosphorylation activity of the recombinant JAK2 kinase via incorporation of ${ }^{32} \mathrm{P}$ from $\gamma^{32} \mathrm{P}[\mathrm{ATP}]$. Specifically, we examined the kinetics of autophosphorylation for two forms of the JAK2 protein: 1) the nonphosphorylated form obtained according to the standard protein purification procedure and 2) the form preautophosphorylated during its purification. The mean level ( \pm standard deviation) of specific activity of the JAK2 kinase domain was $60.5 \pm 1.55 \mathrm{pmol} \cdot \mathrm{mg}^{-1} \cdot \mathrm{min}^{-1}$ and $7.2 \pm 0.03$ $\mathrm{pmol} \cdot \mathrm{mg}^{-1} \cdot \mathrm{min}^{-1}$, respectively. However, the calculated kinase activities had only qualitative significance because we carried out the autophosphorylation reaction under nonsteady-state conditions with a higher concentration of the JAK2 enzyme (acting as an autosubstrate) than of ATP.

We then assessed the effects of a library of 24 CABA derivatives on the autophosphorylation activity of JAK2 at a concentration of $100 \mu \mathrm{M}$. This allowed for selection of potential JAK2 inhibitors (Table 1). We used a low ATP concentration $(0.05 \mu \mathrm{M})$ in the autophosphorylation assay to prevent forfeiture of ATPcompetitive JAK2 inhibitors. Five CABA analogs inhibited the JAK2 autophosphorylation activity by about 50\% (WP1055, WP1065, WP1174, WP1702, and WP1703), and two compounds inhibited it by $88 \%$ (WP1130 and WP1682). These results indicated that these compounds are weak inhibitors of the autophosphorylation activity of JAK2. The inhibition levels allowed for estimation of the $\mathrm{IC}_{50}$ of WP1055, WP1065, WP1174, WP1702, and WP1703 of about $100 \mu \mathrm{M}$ under the assumed reaction conditions. Only WP1130 and WP1682 had an $\mathrm{IC}_{50}$ below $100 \mu \mathrm{M}$ in inhibition of the autophosphorylation activity of JAK2.

\section{Inhibition of JAK2-Catalyzed Phosphorylation}

The peptide used as a reporter reaction substrate was a 20-amino-acid fragment of STAT5 protein containing the tyrosine (Tyr694) that can be phosphorylated by JAK2. We performed the reaction under steady-state conditions. The Michaelis-Menten constant calculated for STAT5 peptide phosphorylation was $126.7 \pm 24.1 \mu \mathrm{M}$. The maximal apparent activity of phosphorylation catalyzed by JAK2 under these conditions reached $1.11 \pm 0.16 \mu \mathrm{mol} \cdot \mathrm{mg}^{-1} \cdot \mathrm{min}^{-1}$. We have reassessed the potency of the known JAK2 inhibitors lestaurtinib and tofacitinib, and their respective $\mathrm{IC}_{50}$ values were $64.4 \mathrm{nM}$ and $106.7 \mathrm{nM}$. In addition, inhibition of phosphorylation activity of JAK2 by the commercially available analog AG490 was in the micromolar range $\left(\mathrm{IC}_{50}=30.4 \mu \mathrm{M}\right)$ and was in agreement with previously reported data [45]. 
We then determined the $\mathrm{IC}_{50}$ values and Hill coefficients of inhibition for selected CABA analogs (Table 2). We derived the parameters from the dose-response curve regression analysis of the JAK2 activity modulated by the inhibitors. Six of the CABA derivatives inhibited the phosphorylation activity of JAK2 at an $\mathrm{IC}_{50}$ less than $20 \mu \mathrm{M}$. These compounds evidently had greater affinity for the activated JAK2 than for the inactive, nonautophosphorylated kinase. Four CABA derivatives-WP1130, WP1682, WP1702, and WP1703 - had similar $\mathrm{IC}_{50}$ s of about $10 \mu \mathrm{M}$. In contrast, the inhibitory activity of WP1130 and WP1682 was higher than that of WP1702 and WP1703 in an autophosphorylation assay (Table 1). This phenomenon may be explained by more than just the higher affinity of WP1702 and WP1703 for the phosphorylated form of JAK2. Additionally, the Hill coefficient was much higher for WP1130 and WP1682 than for WP1702 and WP1703. A coefficient higher than 1 suggests positive cooperativeness of binding (synergism). Consequently, the 80\% inhibitory concentration was much smaller for WP1130 and WP1682 (16.9 $\mu \mathrm{M}$ and $18.5 \mu \mathrm{M}$, respectively) than for WP1702 and WP1703 $(67.6 \mu \mathrm{M}$ and $60.1 \mu \mathrm{M}$, respectively). The Hill coefficients for WP1702 and WP1703 were slightly smaller than 1 (Table 2 ).

To assess the inhibition mechanism, we determined the dose-response fit parameters for various concentrations of the ATP and peptide substrates (Table 3). We observed slightly different behavior of the three inhibitors. The inhibitory activity of WP1065 was statistically invariant in all of the substrate concentrations, indicating that WP1065 may be a noncompetitive inhibitor of JAK2. The $\mathrm{IC}_{50}$ of WP1130 was practically unaffected by ATP and only slightly increased (2.5-fold) at the highest concentration of the STAT5 peptide. Notably, a 10-fold increase in ATP concentration decreased the Hill coefficient for WP1130 from -2.40 to -1.27 . In addition, ATP decreased the synergistic behavior of WP1130. This indicated the significance of the ATP site to the occurrence of WP1130 cooperativeness. We find highly conceivable that at least two molecules of WP1130 bind in the ATP pocket of JAK2. Thus, even though ATP did not cause significant elevation of the $\mathrm{IC}_{50}$ for WP1130, this JAK2 inhibitor may be considered bisubstrate-competitive. Similarly, the increased ATP and peptide concentrations caused 6.1-fold and 3.3-fold increases, respectively, in the $\mathrm{IC}_{50}$ of WP1702. Thus, the competitive behavior of ATP and peptide substrates contributes largely to the JAK2-inhibition mechanism of WP1702. We concluded that CABA analogs behave like noncompetitive or bisubstrate competitive inhibitors.

\section{Binding Sites for the CABA Analogs in JAK2}

We used molecular docking to identify potential sites of binding of CABA analogs to the JAK2 kinase domain. We performed global search analysis for the following JAK2 inhibitors: WP1055, WP1065, WP1174, WP1130, WP1682, WP1702, and WP1703. The plausible binding sites, which are shown in Fig. (3) and Supplementary Table 1, include the ATP pocket, activation-loop pocket, $\alpha$-helix C pocket, and $\beta$ sheet pocket of the N-lobe. Most of these sites are located in the active-site area of JAK2, but the last of these pockets is relatively distinct, and binding of JAK2 inhibitors to this area likely plays a minor role in their inhibition properties.

WP1055, WP1065, and WP1174 are structurally similar (Fig. 1), and this similarity is reflected in their shared binding patterns (Supplementary Table 1), especially for the WP1065 and WP1174 ligands. We found that their binding in the $\alpha$-helix $\mathrm{C}$ pocket had the highest binding energy $\left(-8.23 \mathrm{kcal} \cdot \mathrm{mol}^{-1}\right.$ and -8.48 $\mathrm{kcal} \cdot \mathrm{mol}^{-1}$, respectively) and that they had an optimal hydrogen-bonding network with the amino acids Asp894, Arg975, and Lys999, with potency for pi-cation stacking with Lys999. Arg975, which precedes catalytic Asp976, is important for stabilization of catalytic residues. Lys999 plays the same stabilization role but in reference to the DFG motif. We subjected 10 WP1065-JAK2 initial state complexes corresponding to the main clusters resulting from the molecular docking to 5-ns MD simulation. The results confirmed the preferable binding mode at the activation loop with a conformation of WP1065 penetrating into the $\alpha$-helix C pocket (Supplementary Fig. 3), with the highest mean ( \pm standard deviation) interaction energy being $-54.6 \pm$

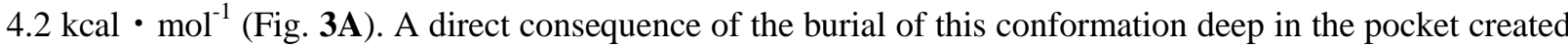
by the activation loop and $\alpha$-helix $\mathrm{C}$ adjacent to the ATP pocket may be an allosteric mode of action of 
WP1065. This observation would be in tune with our enzymatic study results for WP1065 (Table 3), specifically, that neither ATP nor STAT5 peptide affected the WP1065 $\mathrm{IC}_{50}$.

Docking simulation of WP1130 and WP1682 revealed several distinct poses binding between the ATP pocket and activation-loop pocket with similar affinities (Supplementary Table 1). Although the WP1130 conformation in the ATP pocket at the hinge loop had the highest binding energy $\left(-8.27 \mathrm{kcal} \cdot \mathrm{mol}^{-}\right.$

${ }^{1}$ ), it did not form a hydrogen-bonding network. In comparison, the conformations interacting at the interface between the ATP pocket and activation-loop pocket and in the activation-loop pocket itself exhibited the potential to form hydrogen bonds with the conserved amino acids Lys857, Asn859 (glycine loop), Asp976 and Asn981 (catalytic loop), and Glu1015 (activation loop). We carried out MD simulations for 20 WP1130-JAK2 complexes, which indicated two pockets with the most stable poses (Supplementary Fig. 3): the activation-loop pocket $\left(-66.4 \pm 5.7 \mathrm{kcal} \cdot \mathrm{mol}^{-1}\right.$; Fig. 3C) and the ATP pocket $\left(-62.9 \pm 9.2 \mathrm{kcal} \cdot \mathrm{mol}^{-1}\right.$; Fig. 3B). The remaining three most stable WP1130 conformations bound in the ATP pocket with interaction energies of $-53.9 \pm 4.3 \mathrm{kcal} \cdot \mathrm{mol}^{-1},-52.3 \pm 3.4 \mathrm{kcal} \cdot \mathrm{mol}^{-1}$, and $-51.9 \pm 4.6 \mathrm{kcal} \cdot \mathrm{mol}^{-1}$. The natural conclusion is that two distinct WP1130 conformations may interact with the active JAK2 site with similar potency: one in the ATP binding site and the other in the peptide-binding site. This suggests multisite binding and a bisubstrate-competitive mechanism of action of WP1130.

WP1702 and WP1703, which have bulky hydrophobic moieties, bind in the ATP pocket with higher affinities (EB < -9 kcal $\cdot$ mol-1) than those of WP1130 and WP1682 (Supplementary Table 1). The second predominant site of interaction after the ATP pocket was the interface between the ATP pocket and the activation-loop pocket. WP1702 and WP1703 may form hydrogen bonds analogous to those formed by WP1130 and WP1682. MD simulations of 31 WP1702-JAK2 initial conformations identified the four most stable complexes with interaction energies markedly higher than those of the other complexes (Supplementary Fig. 3): $-81.3 \pm 6.0 \mathrm{kcal} \cdot \mathrm{mol}^{-1}$ (Fig. 3D), $-80.3 \pm 10.4 \mathrm{kcal} \cdot \mathrm{mol}^{-1}$ (Fig. 3E), $-74.3 \pm 4.1$ $\mathrm{kcal} \cdot \mathrm{mol}^{-1}$, and $-70.7 \pm 4.5 \mathrm{kcal} \cdot \mathrm{mol}^{-1}$ (Fig. 3F). The first complex binds at the activation loop and penetrates into the ATP pocket; it may disrupt other less stable conformations with the potential to bind in the ATP pocket (the next two conformations) as well as the activation-loop pocket (the fourth conformation). Also, the first most stable conformation may counteract proper binding of both ATP and phosphorylated peptide. Similarly, concentrations of these two substrates influence the $\mathrm{IC}_{50}$ of WP1702 (Table $\mathbf{3}$ ).

The optimal locations of the CABA derivatives in the active site of JAK2, depicted in Fig. (4), reflect the deepest and widest cleft of the JAK2 kinase domain, extending from the hinge loop (ATP pocket) to the $\alpha$-helix C ( $\alpha$-helix C pocket). Binding of the high-energy conformations in the regions directly involved in binding of the ATP and peptide substrates (observed for WP1130 and WP1702) implies a competitive mechanism of JAK2 inhibition. Stable interaction of a conformation deep in the $\alpha$-helix C pocket (observed for WP1065) demonstrates an allosteric mechanism of JAK2 inhibition. We selected the following conformations for schematic representation in Fig. (4) based on the mean interaction energies determined in the MD simulations: WP1065, conformation 1; WP1130, conformations 1, 19, 20, 26, and 50; and WP1702, conformations 1, 2, 3, and 12 (see Supplementary Fig. 3 for an illustration of the statistics regarding the interaction energies).

\section{Structural Interpretation of the Synergistic Binding Mechanism of WP1130}

Our enzymatic results (Table 3) demonstrated that ATP has a strong impact on the Hill coefficient of WP1130: the higher the ATP concentration, the lower the coefficient. Thus, ATP abrogates the synergistic interaction of WP1130 with the active site of JAK2. To gain insight into the cooperative mechanism of binding of WP1130 to JAK2, we combined one of the two distinct high-energy conformations of WP1130 in the ATP-binding site with one of the seven other conformations. The selected poses included not only those with the highest binding energy but also others to keep the group structurally diverse. We carefully optimized the geometry of 14 such co-structures consisting of two molecules of WP1130 in the active JAK2 site. We 
subjected the resulting complexes to 5-ns MD simulations. The energetic advantage of the binding of two ligand molecules in the active site of the JAK2 kinase domain over the binding of one ligand molecule was expressed as follows: $\Delta \mathrm{E}_{\mathrm{A}(\mathrm{P})}+\Delta \mathrm{E}_{\mathrm{B}(\mathrm{P})}+\mathrm{E}_{\mathrm{AB}}$, in which $\Delta \mathrm{E}_{\mathrm{A}(\mathrm{P})}$ is the change in interaction energy between the protein environment and ligand $\mathrm{A}, \Delta \mathrm{E}_{\mathrm{B}(\mathrm{P})}$ is the change in interaction energy between the protein environment and ligand $\mathrm{B}$, and $\mathrm{E}_{\mathrm{AB}}$ is the interaction energy between ligands $\mathrm{A}$ and $\mathrm{B}$. The total energetic gain for the ligand pairs is shown in Fig. (5). The interaction energy increased for 7 of the 14 co-structures, but we saw a positive influence of all three factors $\left(\Delta \mathrm{E}_{\mathrm{A}(\mathrm{P})}, \Delta \mathrm{E}_{\mathrm{B}(\mathrm{P})}\right.$, and $\left.\mathrm{E}_{\mathrm{AB}}\right)$ for only three of them: $2 \& 35(-$ $\left.63.1 \mathrm{kcal} \cdot \mathrm{mol}^{-1}\right), 2 \& 38\left(-45.2 \mathrm{kcal} \cdot \mathrm{mol}^{-1}\right)$, and $2 \& 42\left(-44.1 \mathrm{kcal} \cdot \mathrm{mol}^{-1}\right)$. In general, interaction between two ligand molecules had a positive impact on the binding of the given pair, and this energy may have exceeded $-10 \mathrm{kcal} \cdot \mathrm{mol}^{-1}$ (pair $1 \& 26$ ). However, only a change in the interaction energy with amino acids of the protein environment is decisive. The co-structure with the highest energetic gain, $2 \& 35$, which is depicted in Fig. (4), was only minimally influenced by $\mathrm{E}_{\mathrm{AB}}$ but was greatly influenced by $\Delta \mathrm{E}_{\mathrm{A}(\mathrm{P})}$ and $\Delta \mathrm{E}_{\mathrm{B}(\mathrm{P})}$. These results suggested that synergistic binding of WP1130 results from induced fit transformation of protein cavities in the active JAK2 site upon binding of at least two molecules of WP1130. Regardless of the exact molecular mechanism of the positive cooperativeness of WP1130, our results demonstrated that binding two WP1130 ligand molecules in the active JAK2 site is structurally possible and may be energetically favorable. Why this synergism is possible for WP1130 (and WP1682) but not other structurally close $\mathrm{CABA}$ analogs is unclear and requires further investigation. For ligands with bulky moieties such as WP1702 and WP1703, the natural cause of lack of synergism may result from steric hindrances. This could explain the slightly lower Hill coefficients for these two ligands than for WP1130 and WP1682.

\section{DISCUSSION}

The inhibitors of the JAK2/STAT3 and JAK2/STAT5 signaling pathways described herein are derivatives of natural compounds structurally related to CABA. Analysis of molecular targets for these inhibitors is crucial to understanding their precise mechanisms of action and designing more effective inhibitors of these pathways. Furthermore, identification of their binding sites and specific interactions may be important for future design of high affinity JAK2 inhibitors with specific non-ATP-competitive modes of action. Thus, we studied interactions of selected CABA analogs with JAK2 kinase and identified and characterized structural fragments of the CABA scaffold important for JAK2 inhibition and binding.

The CABA derivatives WP1065, WP1174, WP1130, WP1682, WP1702, and WP1703 exhibited affinity for the JAK2 kinase domain at low micromolar $\mathrm{IC}_{50}$ values ranging from 2.9 to 22.1 that are indicative of only weak inhibition of JAK2. Currently used inhibitors of JAK2 kinase activity have $\mathrm{IC}_{50}$ values in the low nanomolar range (e.g., TG101348 [47], lestaurtinib [48], tofacitinib [49]). However, a potential disadvantage of these inhibitors is their ATP competitiveness, limiting their biological selectivity because of high conservation of ATP binding pockets and concurrent inhibition of multiple kinases. In summary, non-ATP-competitive kinase inhibitors with biologically relevant potency may complement existing ATP-competitive inhibitors by offering increased selectivity and ability to overcome de novo and acquired resistance to ATP-competitive inhibitors [50, 51].

Our results suggested that CABA analogs with the highest affinity for JAK2 behave like allosteric noncompetitive (WP1065) or bisubstrate-competitive (WP1130 and WP1702) inhibitors of JAK2. WP1065 preferentially binds in the $\alpha$-helix $\mathrm{C}$ pocket at the $\mathrm{N}$-terminal portion of the activation loop. Competitive binding of WP1065 at the ATP site or peptide substrate site does not seem probable. Rather, allosteric binding of WP1065 conceivably influences the amino acid environment crucial for proper orientation of the substrate-interacting and catalytic amino acids. Interestingly, WP1065 with an allosteric mechanism of action inhibits the growth of glioma cells [21] and JAK2 enzymatic activity at similar drug concentrations (about $25 \mu \mathrm{M}$ ). On the other hand, both WP1130 and WP1702 seem to interact with JAK2 in two regions: the ATP pocket and peptide substrate site. We propose that the mechanism responsible for the potential positive 
cooperativeness of WP1130 may be the binding of two ligand molecules in the active-site area of JAK2. The diversity in inhibition is a result of subtle structural differences in the inhibitors.

The $\alpha$-helix $\mathrm{C}$ and activation loop regions have relatively little sequence conservation and are characteristic for specific kinase families. Moreover, the amino acids in these two regions can distinguish the JAK subfamilies JAK1, JAK2, JAK3, and TYK2. Among amino acids of JAK2 making contact with WP1065, the only nearly invariant residues in the protein kinase superfamily are Arg975, Gly996, and Leu997 [52]. Four additional residues in the human JAK family are invariant: Phe860, Glu898, Ile901, and Lys999 (Fig. 2A). The pattern of the remaining amino acids (Asp894, Arg897, Thr998, Lys1011, Pro1013, and Gly1014) is unique to particular kinases and may contribute to the selective affinity of ligands for the JAK2 kinase domain. An additional advantage of the inhibitor WP1065 is the relatively high value of the ligand efficiency parameter (0.32). Therefore, allosteric interaction of WP1065 beyond the ATP catalytic site may provide the basis for the design of noncompetitive CABA inhibitors that selectively inhibit the activity of not only JAK family but also subfamily members.

Our conclusion is further supported by studies of allosteric noncompetitive inhibitors of the activity of both serine/tyrosine mitogen-activated protein kinase (MEK) 1 and 2 (PD184352, PD318088, and PD334581) [53, 54, 55]. Identified by our group, the WP1065 binding site is also designated the MEK pocket, which may be used to synthesize novel type III noncanonical kinase inhibitors [56, 57]. In light of these results, we find highly conceivable that the JAK2 kinase inhibitor WP1065 acts in an analogous manner to the allosteric MEK1 and MEK2 inhibitors. These assumptions should be investigated further.

The in vitro anticancer activity of the studied CABA analogs compares very favorably with the activities reported for many natural derivatives of cinnamic acid, such as caffeic acid (3,4-dihydroxycinnamic acid) and its esters. These compounds have attracted much attention owing to their ability to inhibit the growth of neoplastic cells via multiple mechanisms: antioxidant potential, induction of apoptosis, suppression of metastasis, cell-cycle arrest, and immunomodulation [58-61]. Caffeic acid phenethyl ester is one of the most studied CABA analogs. It specifically suppresses activation of the nuclear transcription factor NF- $\mathrm{KB}$ and matrix metalloproteinases (MMP-2 and MMP-9) as well as phosphorylation of AKT kinase (Ak thymoma) and focal adhesion kinase. Importantly, many natural polyphenols, including caffeic acid and its derivatives, are reported to act as micromolar inhibitors of protein kinases [62,63]. The present study confirmed that our selected CABA analogs also directly inhibit JAK2 protein kinase. This demonstrates that further exploration of our findings may lead to the design of therapeutically effective compounds.

\section{CONCLUSIONS}

CABA analogs appeared to be mechanistically diverse inhibitors. We identified 6 of 24 tested compounds as weak inhibitors of phosphorylated (activated) JAK2 with micromolar affinity $\left(\mathrm{IC}_{50} \mathrm{~S}\right.$ ranging from 2.9 to 22.1 $\mu \mathrm{M})$. The JAK2 inhibition and mode of JAK2 binding can be altered by small structural changes and can be either an allosteric noncompetitive (WP1065) or bisubstrate-competitive (WP1130 and WP1702). Our results indicated that direct inhibition of JAK2 enzymatic activity by the CABA derivatives WP1065, WP1130, and WP1702 potentially contributes, albeit minimally, to overall suppression of the JAK2/STAT5 signaling pathway in cancer cells. This study offers a background for the design of novel non-ATP-competitive JAK2 inhibitors with increased selectivity and ability to overcome de novo and acquired resistance to existing inhibitors.

\section{CONFLICT OF INTEREST}

The authors confirm that this article content has no conflicts of interest. Waldemar Priebe holds patents and has a financial interest in the development of selected CABA derivatives. 


\section{ACKNOWLEDGEMENTS}

These studies were supported in part by the Viragh Foundation, the Biocentrum-Ochota project (POIG 02.03.0000-003/09) of the Medical Research Center at the Polish Academy of Sciences, and grant NN 302178238 from the Polish Ministry of Science and Higher Education.

The authors thank Don Norwood for editorial assistance.

\section{REFERENCES}

[1] Schindler, C.; Levy, D. E.; Decker, T. JAK-STAT signaling: from interferon to cytokines. J Biol Chem 2007, 282, 20059-20063.

[2] Tefferi, A.; Pardanani, A. JAK inhibitors in myeloproliferative neoplasms: rationale, current data and perspective. Blood Rev 2011, 25(5), 229-237.

[3] Priebe, W.; Fokt, I.; Szymanski, S.; Madden, T.; Myers, J.; Conrad, C. Orally bioavailable caffeic acid related anticancer drugs. U.S.P. Office $20070232668,2007$.

[4] Priebe, W.; Donato, N.; Talpaz, M.; Szymanski, S.; Fokt, I.; Levitzki, A. Compounds for treatment of cell proliferative diseases. U.S.P. Office 8119827, 2012.

[5] Priebe, W.; Madden, T.; Fokt, I.; Conrad, C. Inhibitors of proliferation and activation of signal transducer and activator of transcription (STATs). U.S.P. Office 8143412, 2012.

[6] De, P.; Baltas, M.; Bedos-Belval, F. Cinnamic Acid Derivatives as Anticancer Agents - A Review. Current Medicinal Chemistry, 2011, 18 (11), 1672-1703.

[7] Faderl, S.; Ferrajoli, A.; Harris, D.; Van, Q.; Priebe, W.; Estrov, Z. WP-1034, a novel JAK-STAT inhibitor, with proapoptotic and antileukemic activity in acute myeloid leukemia (AML). Anticancer Res 2005, 25(3B), 1841-1850.

[8] Gao, H.; Priebe, W.; Glod, J.; Banerjee, D. Activation of Signal Transducers and Activators of Transcription 3 and Focal Adhesion Kinase by Stromal Cell-Derived Factor 1 is required for migration of human mesenchymal stem cells in response to tumor cellconditioned medium. Stem Cells 2009, 27(4), 857865 .

[9] Kong, L.Y.; Abou-Ghazal, M. K.; Wei, J.; Chakraborty, A.; Sun, W.; Qiao, W.; Fuller, G. N.; Fokt, I.; Grimm, E. A.; Schmittling, R. J.; Archer, G. E.; Sampson, J. H.; Priebe, W.; Heimberger, A. B. A novel inhibitor of Signal Transducers and Activators of Transcription 3 activation is efficacious against established central nervous system melanoma and inhibits regulatory T cells. Clin Cancer Res 2008, 14(18), 5759-5768.

[10] Kong, L.Y.; Wei, J.; Sharma, A.; Barr, J.; Abou-Ghazal, M.; Fokt, I.; Weinberg, J.; Rao, G.; Grimm, E.; Priebe, W.; Heimberger, A. A novel phosphorylated STAT3 inhibitor enhances T cell cytotoxicity against melanoma through inhibition of regulatory T cells. Cancer Immunol Immunother 2009, 58(7), 1023-1032.

[11] Kong, L.Y.; Gelbard, A.; Wei, J.; Reina-Ortiz, C.; Wang, Y.; Yang, E.C.; Hailemichael, Y.; Fokt, I.; Jayakumar, A.; Qiao, W.; Fuller, G. N.; Overwijk, W. W.; Priebe, W.; Heimberger, A. B. Inhibition of pSTAT3 enhances IFN- $\gamma$ efficacy against metastatic melanoma in a murine model. Clin Cancer Res 2010, 16(9), 2550-2561.

[12] Samanta, A.; Perazzona, B.; Chakraborty, S.; Sun, X.; Modi, H.; Bhatia, R.; Priebe, W.; Arlinghaus, R. Janus kinase 2 regulates Bcr-Abl signaling in chronic myeloid leukemia. Leukemia 2011, 25(3), 463-472.

[13] Pham, L. V.; Tamayo, A. T.; Li, C.; Bornmann, W.; Priebe, W.; Ford, R. J. Degrasyn potentiates the antitumor effects of bortezomib in mantle cell lymphoma cells in vitro and in vivo: therapeutic implications. Mol Cancer Ther 2010, 9(7), 2026-2036.

[14] Wei, J.; Wu, A.; Kong, L.-Y.; Wang, Y.; Fuller, G.; Fokt, I.; Melillo, G.; Priebe, W.; Heimberger, A. B. Hypoxia potentiates gliomamediated immunosuppression. PLoS One 2011, 6(1), e16195. 
[15] Iwamaru, A.; Szymanski, S.; Iwado, E.; Aoki, H.; Yokoyama, T.; Fokt, I.; Hess, K.; Conrad, C.; Madden, T.; Sawaya, R.; Kondo, S.; Priebe, W.; Kondo, Y. A novel inhibitor of the STAT3 pathway induces apoptosis in malignant glioma cells both in vitro and in vivo. Oncogene 2007, 26(17), 2435-2444.

[16] Kupferman, M. E.; Jayakumar, A.; Zhou, G.; Xie, T.; Dakak-Yazici, Y.; Zhao, M.; Ju, J.; Mandal, M.; Jasser, S.; Madden, T.; Myers, J. N.; Priebe, W. Therapeutic suppression of constitutive and inducible JAKISTAT activation in head and neck squamous cell carcinoma. J Exp Therapeut Oncol 2009, 8(2), 117127.

[17] Hussain, S. F.; Kong, L.-Y.; Jordan, J.; Conrad, C.; Madden, T.; Fokt, I.; Priebe, W.; Heimberger, A. B. A novel small molecule inhibitor of Signal Transducers and Activators of Transcription 3 reverses immune tolerance in malignant glioma patients. Cancer Res, 2007 67(20), 9630-9636.

[18] Ferrajoli, A.; Faderl, S.; Van, Q.; Harris, D. M.; Priebe, W.; Kantarjian, H. M.; Talpaz, M.; Estrov, Z. WP-1066, a nextgeneration member of JAK-Stat inhibitors, induces cell cycle arrest, abrogates proliferation, and induces apoptosis of acute myeloid leukemia (AML) cells. ASH Annual Meeting Abstracts 2004, 104(11), 1169.

[19] Ferrajoli, A.; Faderl, S.; Van, Q.; Koch, P.; Harris, D.; Liu, Z.; Hazan-Halevy, I.; Wang, Y.; Kantarjian, H. M.; Priebe, W.; Estrov, Z. WP1066 disrupts Janus Kinase-2 and induces caspase-dependent apoptosis in acute myelogenous leukemia cells. Cancer Res 2007, 67(23), 11291-11299.

[20] Verstovsek, S.; Manshouri, T.; Quintás-Cardama, A.; Harris, D.; Cortes, J.; Giles, F. J.; Kantarjian, H.; Priebe, W.; Estrov, Z. WP1066, a novel JAK2 inhibitor, suppresses proliferation and induces apoptosis in erythroid human cells carrying the JAK2 V617F mutation. Clin Cancer Res 2008, 14(3), 788-796.

[21] Świątek-Machado, K.; Mieczkowski, J.; Ellert-Miklaszewska, A.; Swierk, P.; Fokt, I.; Szymanski, S.; Skora, S.; Szeja, W.; Grynkiewicz, G.; Lesyng, B.; Priebe, W.; Kaminska, B. Novel small molecular inhibitors disrupt the JAK/STAT3 and FAK signaling pathways and exhibit a potent antitumor activity in glioma cells. Cancer Biol Ther 2012, 13(8), 657-670.

[22] Kapuria, V.; Peterson, L. F.; Fang, D.; Bornmann, W. G.; Talpaz, M.; Donato, N. J. Deubiquitinase inhibition by small-molecule WP1130 triggers aggresome formation and tumor cell apoptosis. Cancer Res 2010, 70(22), 9265-9276.

[23] Kapuria, V.; Levitzki, A.; Bornmann, W. G.; Maxwell, D.; Priebe, W.; Sorenson, R. J.; Showalter, H. D.; Talpaz, M.; Donato, N. J. A novel small molecule deubiquitinase inhibitor blocks Jak2 signaling through Jak2 ubiquitination. Cell Signal 2011, 23(12), 2076-2085.

[24] Bartholomeusz, G. A.; Talpaz, M.; Kapuria, V.; Kong, L. Y.; Wang, S.; Estrov, Z.; Priebe, W.; Wu, J.; Donato, N. J. Activation of a novel Bcr/Abl destruction pathway by WP1130 induces apoptosis of chronic myelogenous leukemia cells. Blood 2007, 109(8), 3470-3478.

[25] Sun, H.; Kapuria, V.; Peterson, L. F.; Fang, D.; Bornmann, W. G.; Bartholomeusz, G.; Talpaz, M.; Donato, N. J. Bcr-Abl ubiquitination and Usp9x inhibition block kinase signaling and promote CML cell apoptosis. Blood 2011, 117(11), 3151-3162.

[26] Jayakumar, A.; Rauvolfowa, J.; Bao, H.; Fokt, I.; Skóra, S.; Heimberger, A.; Priebe, W. Blockade of HIF-1 with a small molecule inhibitor WP1066 in melanoma. Presentation Abstract 3251, AACR Annual Meeting, Washington, DC, 2013.

[27] Mielecki, M.; Krawiec, K.; Kiburu, I.; Grzelak, K.; Zagórski, W.; Kierdaszuk, B.; Kowa, K.; Fokt, I.; Szymanski, S.; Świerk, P.; Szeja, W.; Priebe, W.; Lesyng, B.; LaRonde-LeBlanc, N. Development of novel molecular probes of the Rio1 atypical protein kinase. Biochim Biophys Acta 2013, 1834(7), 1292-1301.

[28] Sanner, M. F. Python: a programming language for software integration and development. J Mol Graph Model 1999, 17(1), 57-61.

[29] Morris, G. M.; Huey, R.; Lindstrom, W.; Sanner, M. F.; Belew, R. K.; Goodsell, D. S.; Olson, A. J. AutoDock4 and AutoDockTools4: automated docking with selective receptor flexibility. J Comput Chem 2009, 30(16), 2785-2791.

[30] Lucet, I. S.; Fantino, E.; Styles, M.; Bamert, R.; Patel, O.; Broughton, S. E.; Walter, M.; Burns, C. J.; Treutlein, H.; Wilks, A. F.; Rossjohn, J. The structural basis of Janus kinase 2 inhibition by a potent and specific pan-Janus kinase inhibitor. Blood 2006, 107(1), 176-183. 
[31] Morris, G. M.; Goodsell, D. S.; Halliday, R. S.; Huey, R.; Hart, W. E.; Belew, R. K.; Olson, A. J. Automated docking using a Lamarckian genetic algorithm and an empirical binding free energy function. $J$ Comput Chem 1998, 19(14), 1639-1662.

[32] Huey R., Morris G.M., Olson A.J., Goodsell D.S. A semiempirical free energy force field with chargebased desolvation. J Comput Chem 2007, 28, 1145-1152.

[33] Duan, Y.; Wu, C.; Chowdhury, S.; Lee, M. C.; Xiong, G.; Zhang, W.; Yang, R.; Cieplak, P.; Luo, R.; Lee, T.; Caldwell, J.; Wang, J.; Kollman, P. A point-charge force field for molecular mechanics simulations of proteins based on condensed-phase quantum mechanical calculations. J Comput Chem 2003, 24(16), 19992012.

[34] Krieger, E.; Darden, T.; Nabuurs, S. B.; Finkelstein, A.; Vriend, G. Making optimal use of empirical energy functions: force-field parameterization in crystal space. Proteins 2004, 57(4), 678-683.

[35] Essmann, U.; Perera, L.; Berkowitz, M. L.; Darden, T.; Lee, H.; Pedersen, L. G. A smooth particle mesh Ewald method. J Chem Phys 1995, 103(19), 8577-8593.

[36] Krieger, E.; Nielsen, J. E.; Spronk, C. A. E. M.; Vriend, G. Fast empirical pKa prediction by Ewald summation. J Mol Graph Model 2006, 25(4), 481-486.

[37] Phillips, J. C.; Braun, R.; Wang, W.; Gumbart, J.; Tajkhorshid, E.; Villa, E.; Chipot, C.; Skeel, R. D.; Kalé, L.; Schulten, K. Scalable molecular dynamics with NAMD. J Comput Chem 2005, 26(16), 1781-1802.

[38] MacKerell Jr., A. D.; Bashford, D.; Bellott; Dunbrack, R. L.; Evanseck, J. D.; Field, M. J.; Fischer, S.; Gao, J.; Guo, H.; Ha, S.; Joseph-McCarthy, D.; Kuchnir, L.; Kuczera, K.; Lau, F. T. K.; Mattos, C.; Michnick, S.; Ngo, T.; Nguyen, D. T.; Prodhom, B.; Reiher, W. E.; Roux, B.; Schlenkrich, M.; Smith, J. C.; Stote, R.; Straub, J.; Watanabe, M.; Wiórkiewicz-Kuczera, J.; Yin, D.; Karplus, M. All-atom empirical potential for molecular modeling and dynamics studies of proteins. J Phys Chem B 1998, 102(18), 35863616.

[39] Jorgensen, W. L.; Chandrasekhar, J.; Madura, J. D.; Impey, R. W.; Klein, M. L. Comparison of simple potential functions for simulating liquid water. J Chem Phys 1983, 79(2), 926-935.

[40] Vanommeslaeghe, K.; Hatcher, E.; Acharya, C.; Kundu, S.; Zhong, S.; Shim, J.; Darian, E.; Guvench, O.; Lopes, P.; Vorobyov, I.; Mackerell Jr., A. D. CHARMM general force field: a force field for drug-like molecules compatible with the CHARMM all-atom additive biological force fields. J Comput Chem $\mathbf{2 0 1 0}$, 31(1096-987X [Electronic]), 671-690.

[41] Vanommeslaeghe, K.; MacKerell Jr., A. D. Automation of the CHARMM General Force Field (CGenFF) I: bond perception and atom typing. J Chem Inf Model 2012, 52(12), 3144-3154.

[42] Vanommeslaeghe, K.; Raman, E. P.; MacKerell Jr., A. D. Automation of the CHARMM General Force Field (CGenFF) II: assignment of bonded parameters and partial atomic charges. J Chem Inf Model 2012, 52(12), 3155-3168.

[43] Larkin, M. A.; Blackshields, G.; Brown, N. P.; Chenna, R.; McGettigan, P. A.; McWilliam, H.; Valentin, F.; Wallace, I. M.; Wilm, A.; Lopez, R.; Thompson, J. D.; Gibson, T. J.; Higgins, D. G. Clustal W and Clustal X version 2.0. Bioinformatics 2007, 23(21), 2947-2948.

[44] Gasteiger, E.; Hoogland, C.; Gattiker, A.; Duvaud, S. E.; Wilkins, M. R.; Appel, R. D.; Bairoch, A. In: The Proteomics Protocols Handbook; Walker, J. M., Ed.; Humana Press: New York, 2005: pp. 571-607.

[45] Duhé, R.J.; Clark, E.A.; Farrar, W. L. Characterization of the in vitro kinase activity of a partially purified soluble GST/JAK2 fusion protein. Mol. Cell. Biochem. 2002, 236, 23-35.

[46] Shultz M.D. Setting expectations in molecular optimizations: strength and limitations of commonly used composite parameters. Bioorg \& Med Chem Let 2013, 23(21), 5980-91.

[47] Wernig, G.; Kharas, M. G.; Okabe, R.; Moore, S. A.; Leeman, D. S.; Cullen, D. E.; Gozo, M.; McDowell, E. P.; Levine, R. L.; Doukas, J.; Mak, C. C.; Noronha, G.; Martin, M.; Ko, Y. D.; Lee, B. H.; Soll, R. M.; Tefferi, A.; Hood, J. D.; Gilliland, D. G. Efficacy of TG101348, a selective JAK2 inhibitor, in treatment of a murine model of JAK2V617F-induced polycythemia vera. Cancer Cell 2008, 13(4), 311-320. [48] Hexner, E. O.; Serdikoff, C.; Jan, M.; Swider, C. R.; Robinson, C.; Yang, S.; Angeles, T.; Emerson, S. G.; Carroll, M.; Ruggeri, B.; Dobrzanski, P. Lestaurtinib (CEP701) is a JAK2 inhibitor that suppresses 
JAK2/STAT5 signaling and the proliferation of primary erythroid cells from patients with myeloproliferative disorders. Blood 2008, 111(12), 5663-5671.

[49] Meyer, D.; Jesson, M.; Li, X.; Elrick, M.; Funckes-Shippy, C.; Warner, J.; Gross, C.; Dowty, M.; Ramaiah, S.; Hirsch, J.; Saabye, M.; Barks, J.; Kishore, N.; Morris, D. Anti-inflammatory activity and neutrophil reductions mediated by the JAK1/JAK3 inhibitor, CP-690,550, in rat adjuvant-induced arthritis. $J$. Inflamm. 2010, 7(1), 41.

[50] Deshpande, A.; Reddy, M.M.; Schade, G.O.M.; Ray, A.; Chowdary, T.K.; Griffin, J.D.; Sattler, M. Kinase domain mutations confer resistance to novel inhibitors targeting JAK2V617F in myeloproliferative neoplasms. Leukemia 2012, 26(4), 708-715.

[51] Hornakova, T.; Springuel, L.; Devreux, J.; Dusa, A.; Constantinescu, S.N.; Knoops, L.; Renauld, J.C. Oncogenic JAK1 and JAK2-activating mutations resistant to ATP-competitive inhibitors. Haematologica 2011, 96(6), 845-853.

[52] Hanks, S. K.; Hunter, T. Protein kinases 6. The eukaryotic protein kinase superfamily: kinase (catalytic) domain structure and classification. FASEB J 1995, 9(8), 576-596.

[53] Dudley, D. T.; Pang, L.; Decker, S. J.; Bridges, A. J.; Saltiel, A. R. A synthetic inhibitor of the mitogenactivated protein kinase cascade. Proc Natl Acad Sci U S A 1995, 92(17), 7686-7689.

[54] Sebolt-Leopold, J. S.; Dudley, D. T.; Herrera, R.; Becelaere, K. V.; Wiland, A.; Gowan, R. C.; Tecle, H.; Barrett, S. D.; Bridges, A.; Przybranowski, S.; Leopold, W. R.; Saltiel, A. R. Blockade of the MAP kinase pathway suppresses growth of colon tumors in vivo. Nat Med 1999, 5(7), 810-816.

[55] Ohren, J. F.; Chen, H.; Pavlovsky, A.; Whitehead, C.; Zhang, E.; Kuffa, P.; Yan, C.; McConnell, P.; Spessard, C.; Banotai, C.; Mueller, W. T.; Delaney, A.; Omer, C.; Sebolt-Leopold, J.; Dudley, D. T.; Leung, I. K.; Flamme, C.; Warmus, J.; Kaufman, M.; Barrett, S.; Tecle, H.; Hasemann, C. A. Structures of human MAP kinase kinase 1 (MEK1) and MEK2 describe novel noncompetitive kinase inhibition. Nat Struct Mol Biol 2004, 11(12), 1192-1197.

[56] Tecle, H.; Shao, J.; Li, Y.; Kothe, M.; Kazmirski, S.; Penzotti, J.; Ding, Y.-H.; Ohren, J.; Moshinsky, D.; Coli, R.; Jhawar, N.; Bora, E.; Jacques-O'Hagan, S.; Wu, J. Beyond the MEK-pocket: Can current MEK kinase inhibitors be utilized to synthesize novel type III NCKIs? Does the MEK-pocket exist in kinases other than MEK? Bioorg Med Chem Lett 2009, 19(1), 226-229.

[57] Palmieri, L.; Rastelli, G. $\alpha \mathrm{C}$ helix displacement as a general approach for allosteric modulation of protein kinases. Drug Discov Today 2013, 18(7-8), 407-414.

[58] Jaganathan, S.K.; Mandal, M. Antiproliferative Effects of Honey and of Its Polyphenols: A Review. Journal of Biomedicine and Biotechnology 2009, 2009.

[59] Lin, H.-P.; Lin, C.-Y.; Huo, C.; Su, L.C.; Chuu, C.P. Anticancer Effect of Caffeic Acid Phenethyl Ester. Pharmacologia 2012, 3(1), 26-30.

[60] Rocha, L.D.; Monteiro, M.C.; Teodoro, A.J. Anticancer Properties of Hydroxycinnamic Acids -A Review. Cancer and Clinical Oncology 2012, 1(2), 109-121.

[61] Chan, G.-F.; Cheung, K.W.; Sze, D.Y. The Immunomodulatory and Anticancer Properties of Propolis. Clinical Reviews in Allergy \& Immunology 2013, 44(3), 262-273.

[62] Levitzki A. Tyrphostins: tyrosine kinase blockers as novel antiproliferative agents and dissectors of signal transduction. The FASEB Journal 1992, 6, 3275-3282.

[63] Lamoral-Theys, D.; Pottier, L.; Dufrasne, F.; Nève, J.; Dubois, J.; Kornienko, A.; Kiss, R.; Ingrassia, L. Natural polyphenols that display anticancer properties through inhibition of kinase activity. Current Medicinal Chemistry 2010, 17(9), 812-825. 
Table 1. Inhibition of the autophosphorylation activity of the JAK2 kinase by selected CABA derivatives.

\begin{tabular}{|c|c|}
\hline CABA derivative & $\begin{array}{c}\text { mean JAK2 activity } \mathbf{\pm} \text { standard } \\
\text { deviation }\left(\mathbf{p m o l} \cdot \mathbf{~} \mathbf{~}^{-1} \cdot \mathbf{m i n}^{-\mathbf{1}} \text { ) }\right.\end{array}$ \\
\hline Control & $74.3 \pm 8.6$ \\
\hline WP1055 & $41.2 \pm 6.6$ \\
\hline WP1065 & $36.8 \pm 3.5$ \\
\hline WP1174 & $33.6 \pm 5.5$ \\
\hline WP1086 & $51.2 \pm 6.7$ \\
\hline WP1130 & $8.5 \pm 0.8$ \\
\hline WP1682 & $8.9 \pm 2.3$ \\
\hline WP1702 & $32.8 \pm 6.0$ \\
\hline WP1703 & $33.8 \pm 0.8$ \\
\hline
\end{tabular}

Table 2. The effects of selected CABA derivatives on JAK2-catalyzed STAT5 peptide phosphorylation.

\begin{tabular}{|c|c|c|}
\hline \multirow{2}{*}{ CABA derivative } & \multicolumn{2}{|c|}{ dose-response fit parameter* } \\
\cline { 2 - 3 } & $\mathbf{I C}_{\mathbf{5 0}}, \boldsymbol{\mu M}(\mathbf{9 5 \%} \mathbf{C I})$ & -Hill coefficient $\mathbf{9 5 \%} \mathbf{C I})$ \\
\hline WP1130 & $9.5(8.8-10.2)$ & $2.40(2.80-2.01)$ \\
\hline WP1682 & $10.3(6.5-16.3)$ & $2.34(3.37-1.30)$ \\
\hline WP1702 & $9.6(5.8-15.8)$ & $0.71(0.94-0.47)$ \\
\hline WP1703 & $9.3(6.7-12.9)$ & $0.76(0.86-0.65)$ \\
\hline WP1065 & $19.9(16.0-24.7)$ & $0.97(1.08-0.87)$ \\
\hline WP1174 & $18.5(15.6-22.0)$ & $1.07(1.18-0.96)$ \\
\hline WP1055 & $43.6(25.5-74.7)$ & $1.01(1.43-0.60)$ \\
\hline
\end{tabular}

${ }^{*}$ Concentration of the substrates in the reaction: $25 \mu \mathrm{M}$ ATP and $300 \mu \mathrm{M}$ STAT5.

Table 3. Inhibition parameters ( $\mathrm{IC}_{50}$ and Hill coefficient) for three CABA derivatives as determined in two sets of substrate (ATP and STAT5 peptide) concentrations.

\begin{tabular}{|c|c|c|c|c|c|}
\hline \multirow{2}{*}{$\begin{array}{c}\text { CABA } \\
\text { derivative }\end{array}$} & \multicolumn{6}{|c|}{ dose-response fit parameter } \\
\cline { 2 - 7 } & $\mathbf{I C}_{\mathbf{5 0}, \boldsymbol{\mu M}(\mathbf{9 5 \%} \mathbf{~ C I})} \begin{array}{c}\mathbf{- H i l l} \text { coefficient } \\
\mathbf{( 9 5 \%} \mathbf{~ C I})\end{array}$ & $\begin{array}{c}\text { Ligand } \\
\text { efficiency* }\end{array}$ & IC $_{\mathbf{5 0}, \boldsymbol{\mu M}(\mathbf{9 5 \%} \mathbf{C I})}$ & $\begin{array}{c}\text {-Hill coefficient } \\
\mathbf{( 9 5 \%} \mathbf{C I})\end{array}$ \\
\hline WP1065 & $14.8(7.9-27.5)$ & $0.96(1.27-0.67)$ & 0.32 & $22.1(13.9-35.0)$ & $1.00(1.38-0.62)$ \\
\hline WP1130 & $3.8(3.5-4.2)$ & $2.09(2.33-1.85)$ & 0.32 & $6.2(5.0-7.8)$ & $1.27(1.59-0.96)$ \\
\hline WP1702 & $2.9(2.1-3.9)$ & $0.91(1.04-0.78)$ & 0.26 & $17.3(12.1-24.8)$ & $1.16(1.53-0.78)$ \\
\hline
\end{tabular}

*Ligand efficiency was calculated according to the equation: $1.4 \cdot\left(-\log \mathrm{IC}_{50}\right) / \mathrm{N}, \mathrm{N}$ is the number of nonhydrogen atoms [46]. 
cinnamic acid<smiles>O=C(O)/C=C/c1ccccc1</smiles>
WP1055<smiles>N#C/C(=C\c1ccccn1)C(=O)NCc1ccccc1</smiles>
WP1065<smiles>C[C@H](NC(=O)/C(C#N)=C/c1ccccn1)c1ccccc1</smiles>
WP1174<smiles>C[C@H](NC(=O)/C(C#N)=C/c1ccccn1)c1ccccc1</smiles><smiles>CCC[C@@H](NC(=O)/C(C#N)=C/c1cccc(Br)n1)c1ccccc1</smiles><smiles>CCCC(NC(=O)/C(C#N)=C/c1ccc(Br)cn1)c1ccccc1</smiles><smiles>N#C/C(=C\c1cccc(Br)n1)C(=O)N[C@H](CCCc1ccccc1)c1ccccc1</smiles><smiles>N#C/C(=C\c1ccc(Br)cn1)C(=O)NC(CCCc1ccccc1)c1ccccc1</smiles>

Fig. (1). Representative structures of the analogs of cinnamic acid benzyl amide used in this study. 
JAK1 LPSGSLKEYLPKNKNK IN LKQQUKYAVOTCKGMDYLGSROYVHRDLAARNVLVESEHOVKIGDFGLTKAIETDKEYYTVKDDRDSPVFWYAPECL JAK3 LPSGCLRDFLQRHRARLDASRLLLYSSOICKGMEYLGSRRCVHRDLAARNITVESEAHVKIADFGLAKLLP LDEYYVVREPGQSPIFWYAPES TYK2 VPLGSLRDYLPR - -HS IGLAQLLLFAQQICEGMAYLHAOHYIHRDLAARNVLLDNDRLVKIGDFGLAKAVPEGHEYYRVREDGDSPVFWYAPECL
JAK2 LPYGSLRDYLQKHKERIDHIKLLQYTSOICKGMEYLGTKRYIHRDLATRNILVENENRVKIGDFGLTKVLPQDKEYYKVKEPGESPIFWYAPESL LPYGSLRDYLQK catalytic-loofe activation loop

JAK1 MOSKFYIASDVWSFGVTLHELLTYCDSDSSPMALFLKMIG-PTHGOMTVTRLVNTIKEGKRIPCPPNCPDEVYOLMRKCWEFOPSNRTSFONLIE JAK3 SDNIESROSDVWSFGVVLYELFTYCDKSCSPSAEFLRMMG-CERDVPALCRLLELLEEGORLPAPPACPAEVHELMK LCWAPSPQDRPSFSALGP TYK2 KEYKFYYASDVWSFGVTLYELLTHCDSSOSPPTKFLELIG-IAOGOMTVLRLTELLERGERLPRPDK CPCEVYHLMKNCWETEASFRPTFENLIP JAK2 TESKFSVASDWWSFGVVLYELFTY IEKSK SPPAEFMRMIGNDKQGQMIVFHLIELIKNNGRLPRPDGCPDEIYMIMTECWNNNVNQRPSFRDLAL insertion loop

B

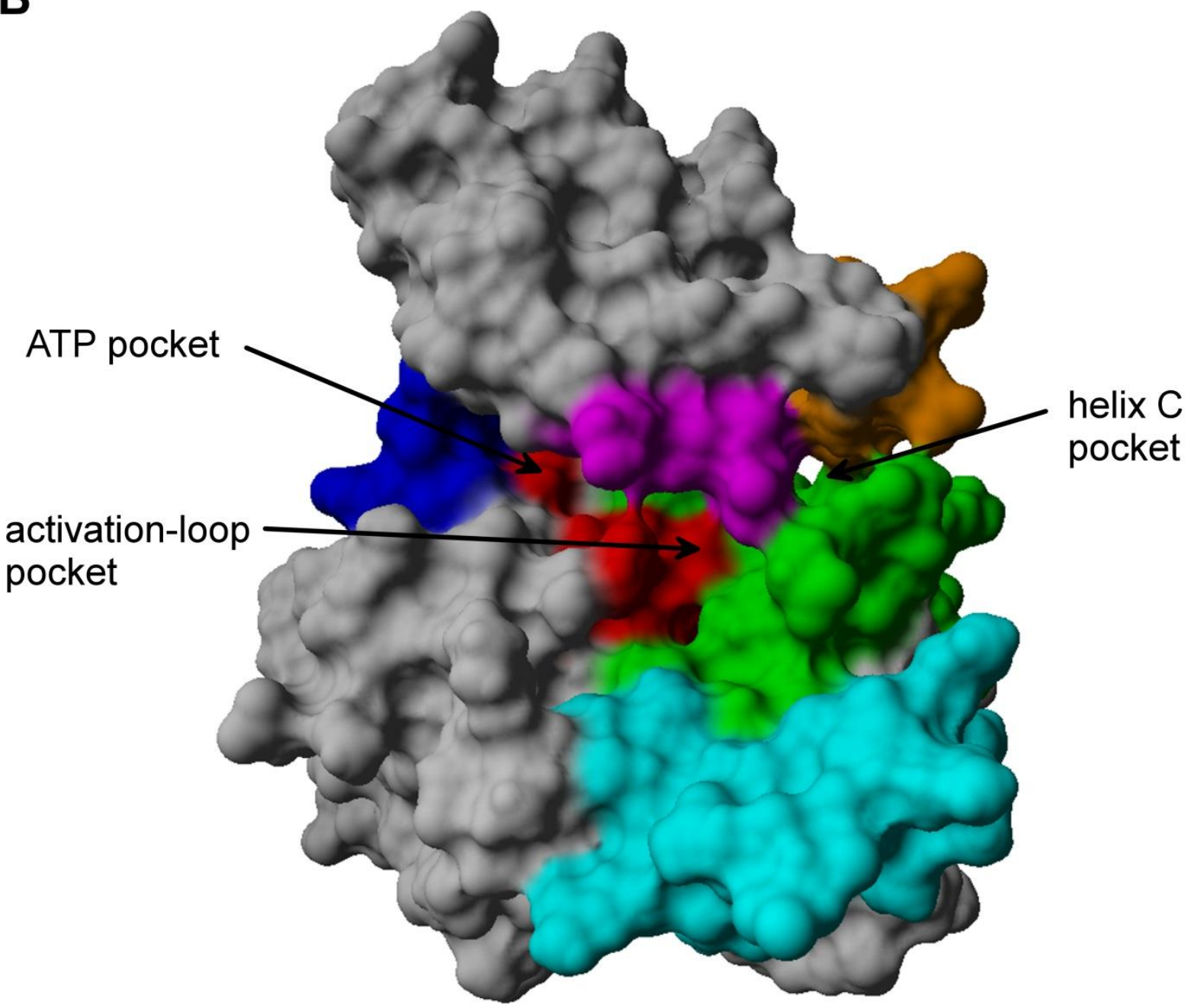

Fig. (2). Structure of the JAK2 kinase domain with its conserved elements. A) Multiple sequence alignment of the human JAK kinase family-JAK1, JAK2, JAK3, and TYK2 - with the features of the active site marked. The hinge loop encompasses amino acids 929-935 (MEYLPYG), the glycine loop encompasses amino acids 856-861 (GKGNFG), the protein tyrosine kinase active-site signature (catalytic loop) encompasses amino acids 972-984 (YIHRDLATRNILV), and the activation loop encompasses amino acids 994-1023 (with both the DFG triplet 994-996 and autophosphorylated Y1007/Y1008). B) Binding sites of the CABA derivatives on the JAK2 kinase domain surface as determined via molecular docking. Four regions in the vicinity of crucial structural elements were detected: the ATP pocket, activation-loop pocket, $\alpha$-helix C pocket, and $\beta$-sheet pocket of the N-lobe. The first two regions are located in the active site of the JAK2 kinase domain and form large binding cavity. The third region neighbors the active site. The fourth region is quite distant from the active JAK2 site. 

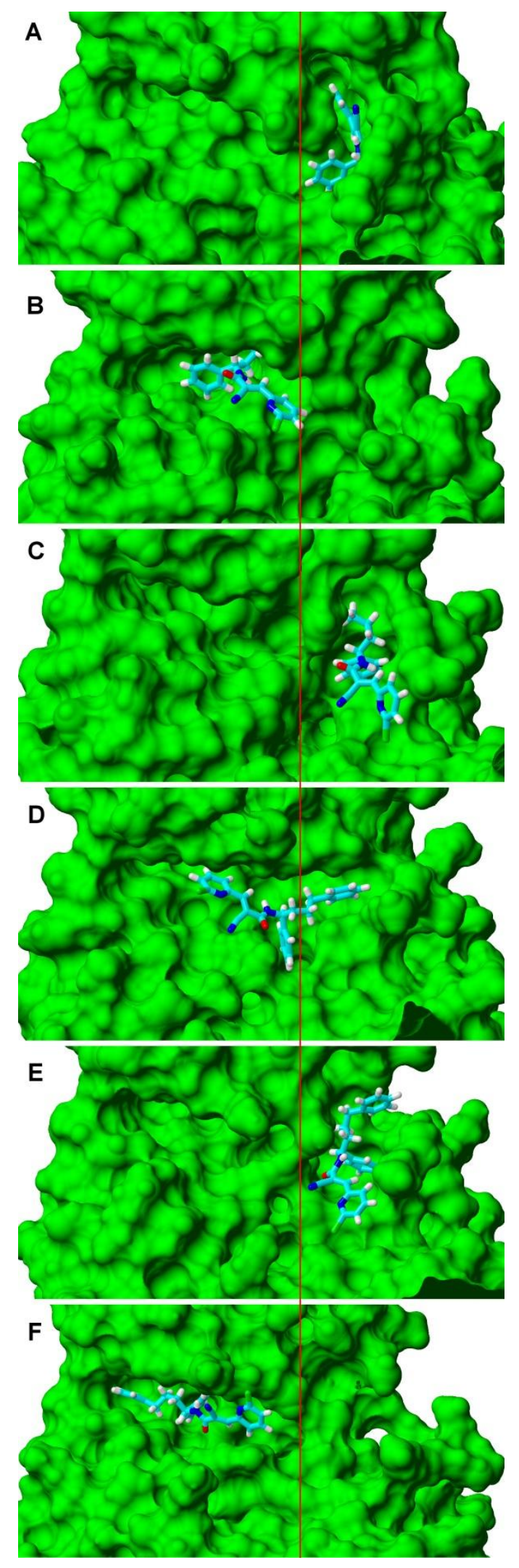

Fig. (3). High-energy poses of the representative CABA ligands WP1065, WP1130, and WP1702. A) WP1065 was buried deep in the $\alpha$-helix C pocket at the activation loop and at the $\alpha$-helix C. B) and C) WP1130 bound in two regions with similar affinity: the ATP pocket (B) and activation-loop pocket (C). D-F) WP1702 also bound with similar affinity in the ATP pocket (F) and activation-loop pocket (E) as well as at the interface between these two cavities (D). The vertical line separates the active site of JAK2: the left side contains the ATP-pocket region, and the right side contains the activation loop engaged in peptide substrate recognition. 


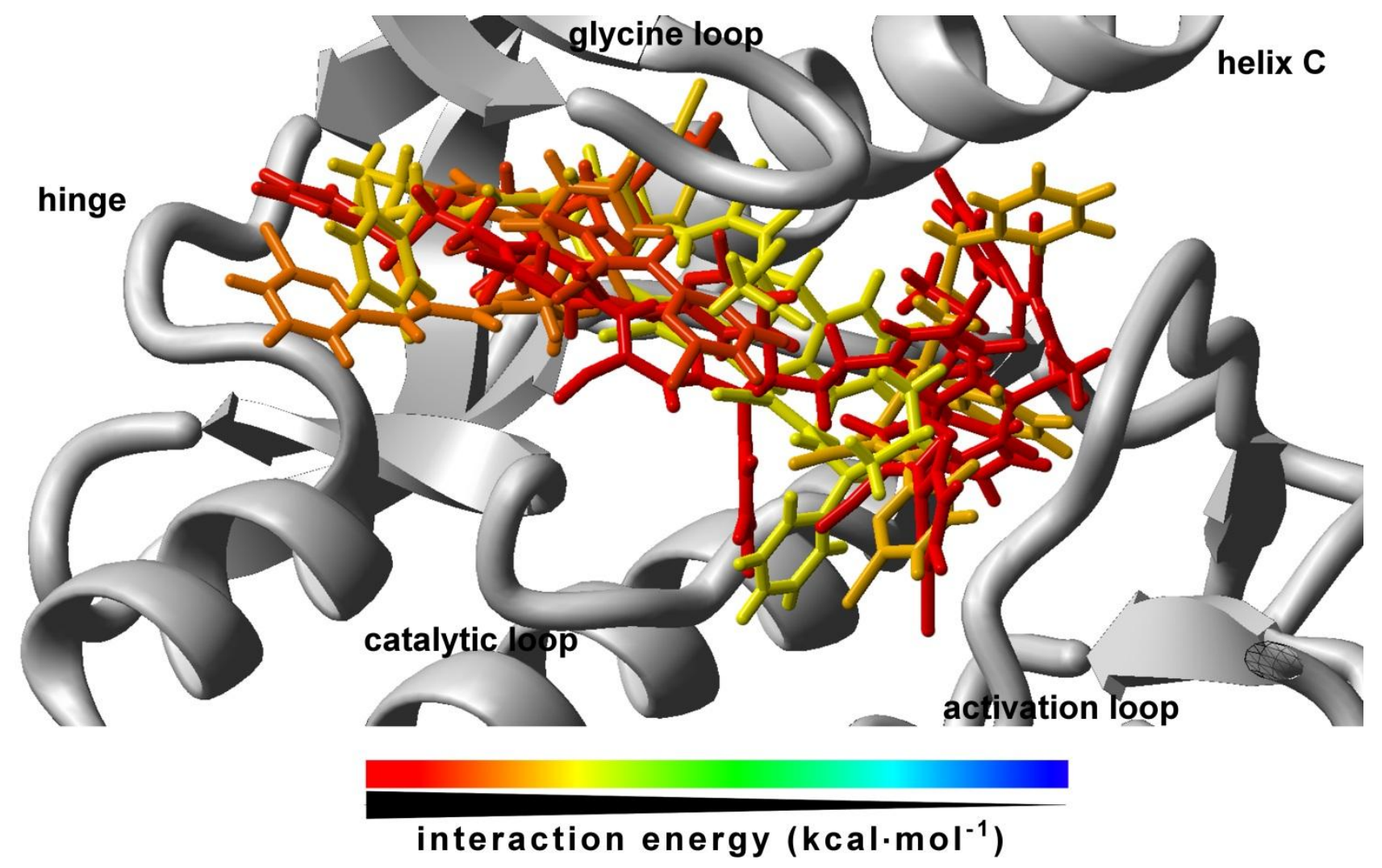

Fig. (4). The most optimal locations of the CABA derivatives in the JAK2 catalytic domain. The following conformations were selected for comparison of their binding poses based on their mean interaction energies as determined in MD simulations: WP1065, conformation 1; WP1130, conformations 1, 19, 20, 26, and 50; WP1702, conformations 1, 2, 3, and 12 (see Supplementary Fig. 3 for an illustration of the statistics of the interaction energies). The different colors correspond to magnitudes of the interaction energies: -54.6 $\mathrm{kcal} \cdot \mathrm{mol}^{-1}$ (red) to $-11.3 \mathrm{kcal} \cdot \mathrm{mol}^{-1}$ (blue) for WP1065, $-66.4 \mathrm{kcal} \cdot \mathrm{mol}^{-1}$ (red) to $-7.3 \mathrm{kcal} \cdot \mathrm{mol}^{-1}$ (blue) for WP1130, and $-81.3 \mathrm{kcal} \cdot \mathrm{mol}^{-1}$ (red) to $-24.0 \mathrm{kcal} \cdot \mathrm{mol}^{-1}$ (blue) for WP1702. 

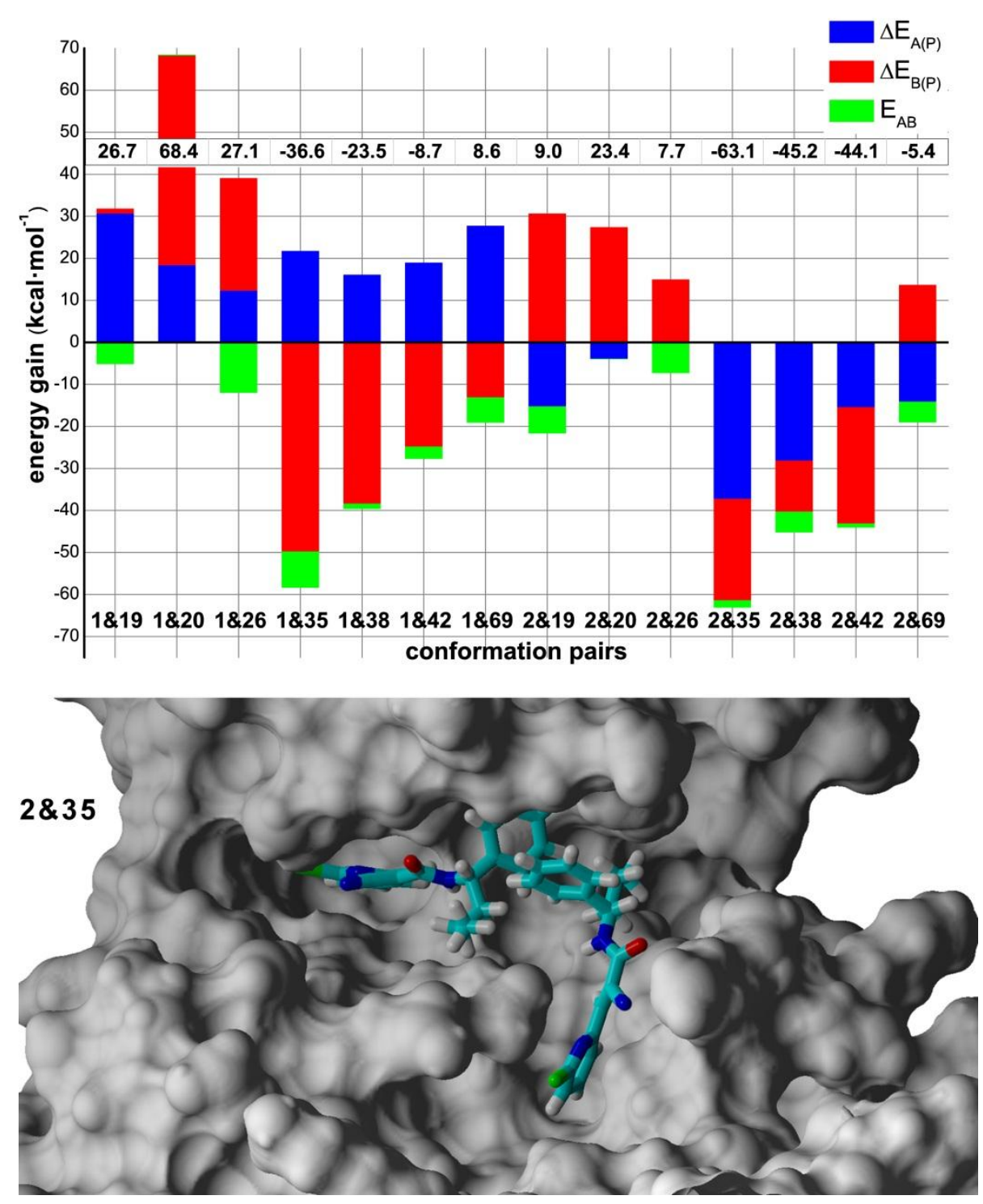

Fig. (5). Change in the interaction energy of WP1130 as a result of synergistic binding of two molecules of this ligand in the active center of JAK2. Energetic gain by binding of two WP1130 molecules was expressed as $\Delta \mathrm{E}_{\mathrm{A}(\mathrm{P})}+\Delta \mathrm{E}_{\mathrm{B}(\mathrm{P})}+\mathrm{E}_{\mathrm{AB}}$, in which $\Delta \mathrm{E}_{\mathrm{A}(\mathrm{P})}$ is the change in interaction energy between the protein environment and ligand $\mathrm{A}, \Delta \mathrm{E}_{\mathrm{B}(\mathrm{P})}$ is the change in interaction energy between the protein environment and ligand $\mathrm{B}$, and $\mathrm{E}_{\mathrm{AB}}$ is the interaction energy between ligands $\mathrm{A}$ and $\mathrm{B}$. The most stable co-structure of two WP1130 molecules in the active site of JAK2 (pair $2 \& 35$ ) is shown below the graph. 


\section{SUPPORTIVE/SUPPLEMENTARY MATERIAL}

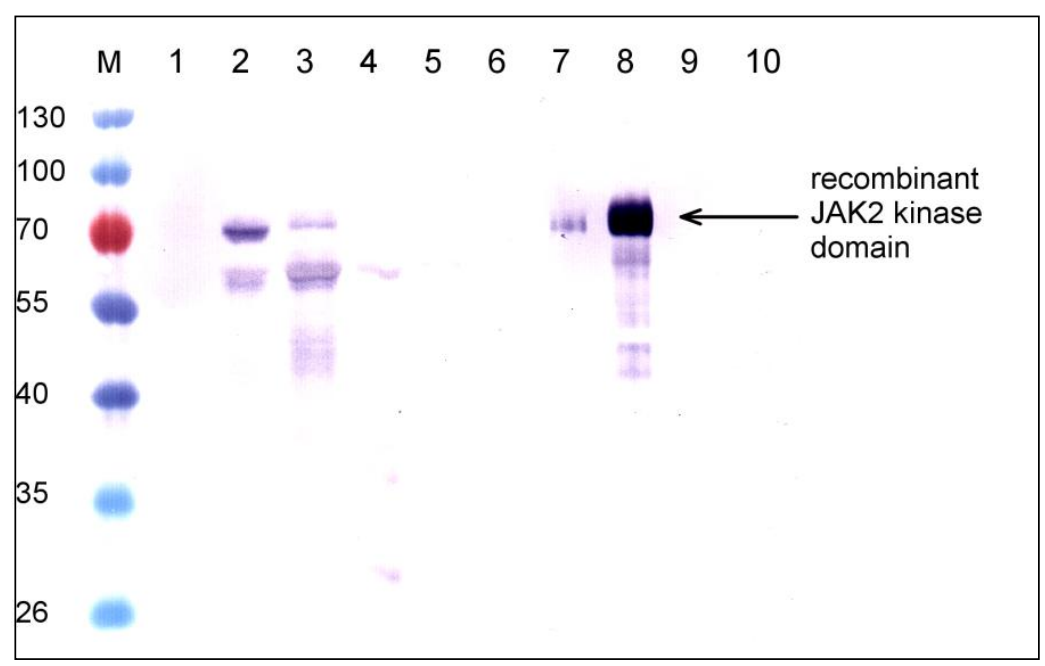

Supplementary Fig. (1). Purification of the recombinant JAK2 kinase domain. Western blot analysis of the kinetics of expression of the recombinant JAK2 kinase domain with N-terminal GST, S and hexahistidine tags (molecular weight, $70 \mathrm{kDa}$ ) in insect cell lysates with an anti-HIS antibody (Abcam). Membrane lanes 1-5 correspond to the lysate supernatants, and lanes 6-10 correspond to the lysate pellets. M, protein marker (numbers are molecular weights in $\mathrm{kDa}$ ); lanes 1 and 6,0 hours after infection; lanes 2 and 7, 24 hours after infection; lanes 3 and 8, 48 hours after infection; lanes 4 and 9, 72 hours after infection; and lanes 5 and 10, 96 hours after infection. The highest level of expression of the soluble form of the recombinant kinase was observed at 24 hours after infection (band migration at $70 \mathrm{kDa}$ ). Forty-eight hours after infection and later, the full-length recombinant protein both was proteolyzed and accumulated in pellets in an insoluble form.

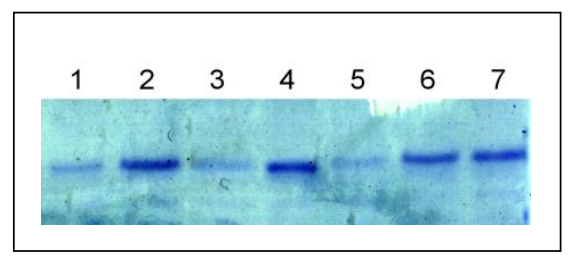

Supplementary Fig. (2). The stability of the JAK2 kinase domain in buffers containing $0.1 \%$ detergents: lane 1, control without a detergent; lane 2, Triton X-100; lane 3, CHAPS; lane 4, Thesit; lane 5, Tween-20; lane 6, DDM; and lane 7, Brij 35. The concentration of the soluble form of the JAK2 kinase domain was analyzed using SDS-PAGE after thrombin-directed proteolysis of the fusion protein and release of it from glutathione-agarose beads. The JAK2 kinase domain was visibly stabilized in solution by four detergents: Triton X-100, Thesit, DDM, and Brij 35. 
Supplementary Table 1. Binding regions of CABA derivatives in the JAK2 kinase domain identified in molecular docking simulations.*

\begin{tabular}{|c|c|c|c|c|c|c|c|c|}
\hline \multirow{2}{*}{\multicolumn{2}{|c|}{ inhibitor }} & \multicolumn{7}{|c|}{ region of binding } \\
\hline & & \multirow{2}{*}{\begin{tabular}{|c|} 
ATP pocket \\
6.98 \\
\end{tabular}} & \multirow{2}{*}{\multicolumn{3}{|c|}{\begin{tabular}{|c|}
$\begin{array}{c}\text { interface between ATP and activation loop } \\
\text { pocket }\end{array}$ \\
- \\
\end{tabular}}} & \multirow{2}{*}{\begin{tabular}{|c|}
$\begin{array}{c}\text { activation loop } \\
\text { pocket }\end{array}$ \\
6.90 \\
\end{tabular}} & \multirow{2}{*}{$\begin{array}{c}\alpha \text { helix } C \\
\text { pocket }\end{array}$} & \multirow{2}{*}{\begin{tabular}{|c|}
$\begin{array}{c}\boldsymbol{\beta} \text { sheet pocke } \\
\text { of the } \mathbf{N} \text {-lobe }\end{array}$ \\
7.26 \\
\end{tabular}} \\
\hline \multirow[b]{2}{*}{ WP1055 } & $-E_{B}$ & & & & & & & \\
\hline & $\mathrm{HB}$ & Leu932 (6.91) & & - & & Glu1015 (0.18) & \begin{tabular}{|l|} 
Arg975 $(4.71)$ \\
Asp894 (2.23) \\
Lys999 (0.05) \\
\end{tabular} & $\begin{array}{l}\text { Gln906 (3.45) } \\
\text { Tyr913 (4.42) } \\
\text { Tyr913 (5.20) }\end{array}$ \\
\hline \multirow[b]{2}{*}{ WP1065 } & $-E_{B}$ & 7.00 & & 6.74 & & 7.03 & 8.23 & 7.18 \\
\hline & $\mathrm{HB}$ & - & & $\begin{array}{l}\text { Asn859 (4.89) } \\
\text { Asp976 (2.99) }\end{array}$ & & Glu1015 (6.56) & $\begin{array}{l}\text { Arg975 (5.00) } \\
\text { Asp894 (2.68) } \\
\text { Lys999 (0.17) } \\
\end{array}$ & Tyr913 (7.46) \\
\hline \multirow[b]{2}{*}{ WP1174 } & $-\mathrm{E}_{\mathrm{B}}$ & 7.47 & & 7.00 & & 7.07 & 8.48 & 7.60 \\
\hline & HB & $\begin{array}{l}\text { Tyr931 (1.92) } \\
\text { Leu932 (3.25) }\end{array}$ & & $\begin{array}{l}\text { Arg980 (5.14) } \\
\text { Asn981 (0.19) }\end{array}$ & & Glu1015 (2.93) & \begin{tabular}{|l|} 
Arg975 $(5.10)$ \\
Asp894 (2.50) \\
Lys999 $(0.05)$
\end{tabular} & $\begin{array}{l}\text { Tyr913 (3.24) } \\
\text { Tyr913 (6.36) }\end{array}$ \\
\hline \multirow[b]{2}{*}{ WP1130 } & $-E_{B}$ & 8.27 & 7.61 & 7.51 & 7.77 & 7.75 & 7.22 & 7.17 \\
\hline & HB & - & $\begin{array}{l}\text { Asn859 (4.25) } \\
\text { Asp976 (0.58) }\end{array}$ & $\begin{array}{l}\text { Lys857 (5.00) } \\
\text { Asn981 (3.63) }\end{array}$ & $\begin{array}{l}\text { Asn981 (0.56) } \\
\text { Asn981 (1.83) }\end{array}$ & Glu1015 (2.09) & $\operatorname{Arg} 975$ (4.79) & $\begin{array}{l}\text { Gln906 (4.93) } \\
\text { Tyr913 (0.16) }\end{array}$ \\
\hline \multirow[b]{2}{*}{ WP1682 } & $-E_{B}$ & 7.90 & 7.34 & 7.15 & 6.98 & 7.63 & 7.04 & - \\
\hline & HB & - & Asn859 (6.20) & $\begin{array}{l}\text { Asn859 (4.46) } \\
\text { Arg980 (4.48) }\end{array}$ & $\begin{array}{l}\text { Asn859 (4.63) } \\
\text { Asn981 (5.94) }\end{array}$ & Glu1015 (5.63) & $\operatorname{Arg} 975$ (3.39) & - \\
\hline \multirow[b]{2}{*}{ WP1702 } & $-\mathrm{E}_{\mathrm{B}}$ & 9.07 & & 9.61 & & 9.31 & 8.56 & - \\
\hline & HB & - & & $\begin{array}{l}\text { Asn859 (4.20) } \\
\text { Asp976 (2.72) }\end{array}$ & & Glu1015 (7.78) & - & - \\
\hline \multirow[b]{2}{*}{ WP1703 } & $-E_{B}$ & 9.33 & 9.42 & 8.39 & 8.60 & 8.76 & 8.31 & - \\
\hline & $\mathrm{HB}$ & - & $\begin{array}{l}\text { Asn859 (6.28) } \\
\text { Asp976 (2.90) }\end{array}$ & $\begin{array}{l}\text { Asn859 (3.83) } \\
\text { Arg980 (3.11) }\end{array}$ & $\begin{array}{l}\text { Asn859 (4.64) } \\
\text { Asn981 (4.74) }\end{array}$ & Glu1015 (6.74) & Lys999 (2.77) & - \\
\hline
\end{tabular}

*The binding energy of poses $\left(\mathrm{E}_{\mathrm{B}}, \mathrm{kcal} \cdot \mathrm{mol}^{-1}\right)$ as well as hydrogen bonding $(\mathrm{HB})$ to JAK2 amino acids (with indicated energies in $\mathrm{kcal} \cdot \mathrm{mol}^{-1}$ ) were computed using the AutoDock software program (version 4.2). 
Supplementary Fig. (3). Mean interaction energies (with standard deviations) for the CABA derivatives WP1065, WP1130, and WP1702 and the protein environment $\left(\mathrm{kcal} \cdot \mathrm{mol}^{-1}\right)$ after 5-ns molecular dynamics simulation of the complexes CABA-JAK2. The conformation numbers correspond to the initial ligand states that resulted from molecular docking. Double color of a column indicates that this particular conformation locates in the interface between two pockets and thus may sterically block binding of other conformations in both pockets.
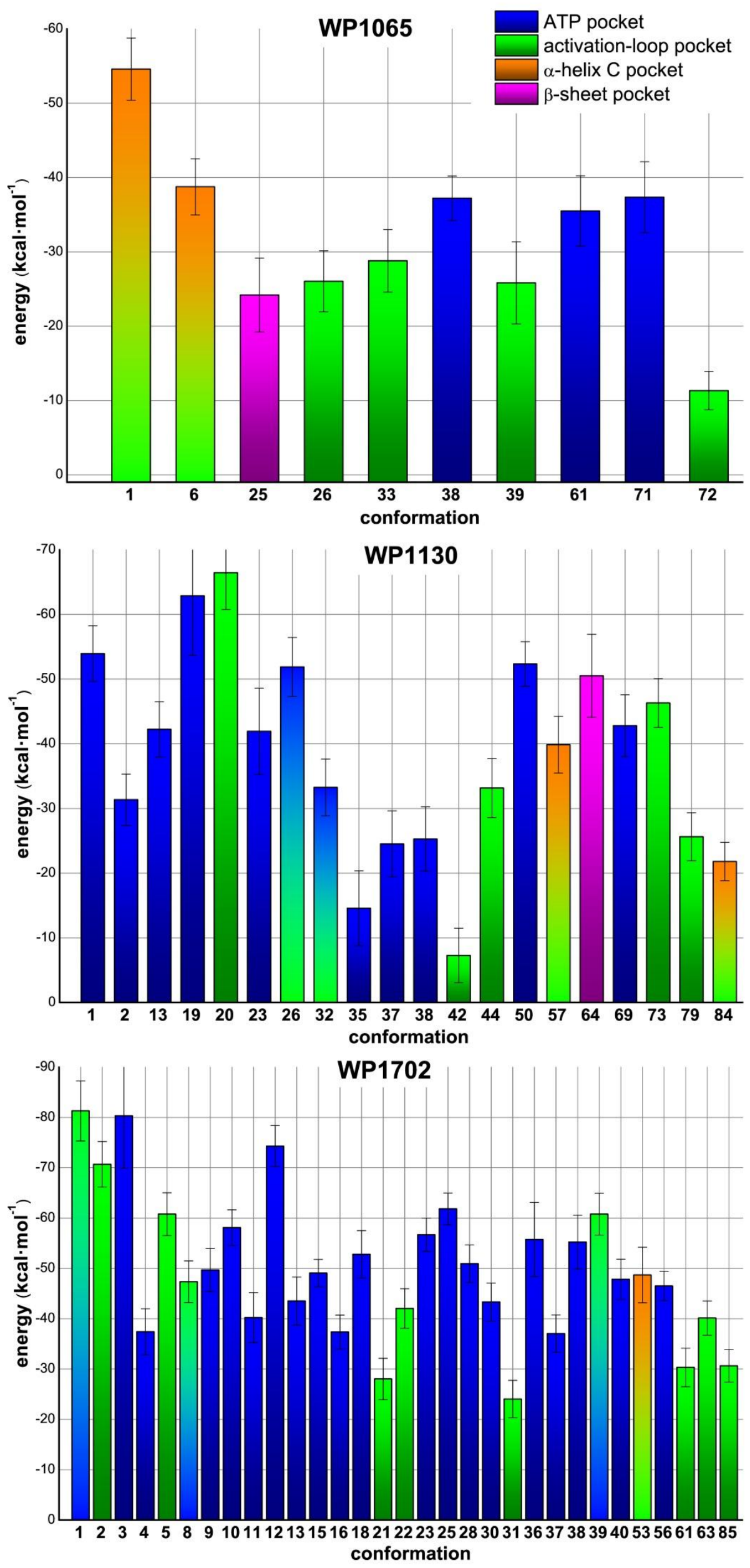